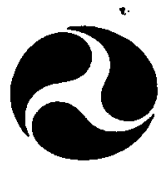

U.S. Department of Transportation

National Highway

Traffic Safely

Administration

Final Report

\title{
Site Report: Wichita, Kansas Field Test of Combined Speed, Alcohol, and Safety Belt Enforcement Strategies
}


This publication is distributed by the U.S. Department of Transportation, National Highway Traff tration, in the interest of information exchange. The opinions, findings and conclusions expressed in this publication are those of the author(s) and not necessarily those of the Department of Transportation or the National Yighway Traffic Safety Administration. The United States Government assumes no liability for its contents or use thereof. If trade or manufacturers' name or products are mentioned, it is because they are considered essential to the object of the publication and should not be construed as an endorsement. The United States Government does not endorse products or manufacturers. 


\begin{tabular}{|c|c|}
\hline 2. Government Accession No. & 3. Recipient s Colaiog No. \\
\hline 4. Titie and Subtitle Site Report: Wichita, Kansas & $\begin{array}{l}\text { March } 1995\end{array}$ \\
\hline Safety Belt Enforcement Strategies & 6. Performing Organization Code \\
\hline $\begin{array}{l}\text { 7. Author's) Jones, R.; Joksch, H.; Lacey, J.; } \\
\text { Wiliszowski, C.; and Marchetti, L. }\end{array}$ & 8. Performing Organization Report No. \\
\hline $\begin{array}{l}\text { 9. Perfarming Organization Name and Address } \\
\text { Mid-America Research Institute }\end{array}$ & 10. Work Unit No. (TRAIS) \\
\hline $\begin{array}{l}611 \text { Main Street } \\
\text { Winchester, MA } 01890\end{array}$ & $\begin{array}{l}\text { 17. Contract or Grant No. } \\
\text { DTNH22-89-C }-07396\end{array}$ \\
\hline (1) & 13. Type of Report and Period Covered \\
\hline $\begin{array}{l}\text { 12. Sponsoring Agency Nome and Address } \\
\text { National Highway Traffic Safety Administration } \\
\text { Office of Program Development and Evaluation }\end{array}$ & $\begin{array}{l}\text { Final Report } \\
9 / 89-4 / 94\end{array}$ \\
\hline $\begin{array}{l}4007 \text { th Street, S.W. } \\
\text { Washington, DC } 20590\end{array}$ & 14. Sponsoring Ageney Code \\
\hline
\end{tabular}

Ted Anderson served as COTR on the project.

16. Abstroct

This report describes the implementation and evaluation of a traffic safety program in Wichita, Kansas. The goal of the program was to reduce the incidence of speeding, alcohol-impaired driving (DWI) and rion-use of safety belts through well-publicized enforcement strategies focusing attention on all three areas. The wichita Police Department selected "Traffic Trifecta: Buckle Up - Slow Down - Drive Sober. Don't gamble with a life!" as the theme for their program. The program sequentially emphasized five different combined enforcement strategies over a period of approximately one year. A public information and education program that focused on each strategy ran for about two months. Though several unusual occurrences including abortion protests, severe. weather conditions and increased gang-related activities taxed police resources there was a significant increase in DWI enforcement and associated reductions in alcohol-related crashes. Speeding enforcement activity actually decreased somewhat during the project period and thus there were no positive changes in speed outcome measures. Even though there were moderate increases in safety belt enforcement activity, belt use did not increase. It is concluded that the competing demands of non-traffic enforcement activities prevented a fair test of the combined enforcement concept in Wichita.

17. Key Words

Speeding, DWI, safety belts, enforcement, evaluation
18. Distribution Stotement

This document is available to the U.S. public through the National Technical Information Service, Springfield, VA 22161

\begin{tabular}{|l|l|l|l|}
\hline 19. Security Classif. (of this report) & 20. Security Clossif..(of this page) & 21. No. of Poges & 22. Price \\
\hline
\end{tabular}




\section{ACKNOWLEDGEMENTS}

The authors are grateful to the many individuals who helped with this project. We would like to offer a special thanks to Rosalie Thornburgh, the Kansas Traffic Safety Administrator, for her assistance and guidance throughout the project.

The actual execution of the test program was performed entirely by the Wichita Police Department (WPD). We are grateful to Chief Rick Stone and Deputy Chief Steve Trainer for promoting the implementation of the program in Wichita and Major $\mathrm{K}$. Tyler Brewer for his direction and support of the Traffic Trifecta project: We would especially like to thank Lieutenant Ronald R. Harris for coordinating the WPD effort both within the department and in the community. Through his efforts local resources were obtained to support the project. We are most grateful to those in the local media who contributed their time and resources in support of the public information component of the project. The efforts of Donrey Advertising in designing the project logo and in donating billboards was greatly appreciated, as well as the efforts of television stations KSNW and KWCH for taping and airing the PSAs.

Topeka was the comparison site for the Wichita project. We would like to thank Captain Dean Forrester and Missy Cowhick of the Topeka Police Department for providing information and data relating to Topeka and Shawnee County.

We would especially like to recognize those in state and local government agencies in Kansas who assisted us. Jim Schaller, Research Analyst with the Office of Traffic Safety, provided accident data tapes. The surveys of driver attitudes and behavior were conducted in the Drivers Licensing Offices in Wichita and Topeka. We would like to thank John Smith, Administrator of Driver Control, and Sondra Dexter, Chief-Driver License Examining, for their support of our survey efforts with special thanks to Hazel Balthazor of the Topeka Licensing Office for overseeing the collection efforts in Topeka.

Mid-America was supported in this project by the Center for Applied Research (CAR). Marsha Nitzberg and Drew Knoblauch of CAR played key roles in collecting field data of vehicle speeds and seatbelt use in Wichita and Topeka.

We thank all who assisted in the planning, implementation, data collection and analyses of the Kansas project. 


\section{TABLE OF CONTENTS}

ACKNOWLEDGEMENTS $\ldots \ldots \ldots \ldots \ldots \ldots \ldots \ldots \ldots \ldots \ldots \ldots \ldots \ldots \ldots \ldots$

TABLE OF CONTENTS $\ldots \ldots \ldots \ldots \ldots \ldots \ldots \ldots \ldots \ldots \ldots, \mathrm{v}$

FIGURES $\ldots \ldots \ldots \ldots \ldots \ldots \ldots \ldots \ldots \ldots \ldots \ldots \ldots \ldots \ldots \ldots \ldots \ldots \ldots \ldots$

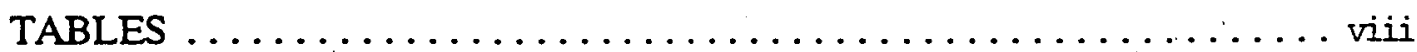

EXECUTTVE SUMMARY $\ldots \ldots \ldots \ldots \ldots \ldots \ldots \ldots \ldots \ldots \ldots \ldots \ldots \ldots \ldots$

1 - INTRODUCTION $\ldots \ldots \ldots \ldots \ldots \ldots \ldots \ldots \ldots \ldots \ldots \ldots \ldots \ldots \ldots \ldots \ldots \ldots$

GENERAL NATURE OF THE PROJECT $\ldots \ldots \ldots \ldots \ldots \ldots \ldots \ldots$

PROJECT SCOPE AND APPROACH $\ldots \ldots \ldots \ldots \ldots \ldots \ldots \ldots \ldots, 1$

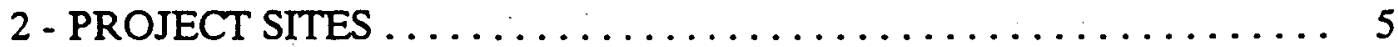

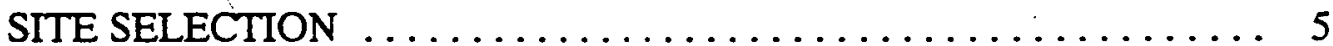

TEST SITE DESCRIPTION $\ldots \ldots \ldots \ldots \ldots \ldots \ldots \ldots \ldots \ldots, 6$

COMPARISON SITE DESCRIPTION .................. 7

SUMMARY OF CHARACTERISTICS OF THE TEST SITE AND THE COMPARISON SITE $\ldots \ldots \ldots \ldots \ldots \ldots \ldots \ldots \ldots \ldots, 8$

3 - PROJECT DESCRIPTION $\ldots \ldots \ldots \ldots \ldots \ldots \ldots \ldots \ldots \ldots \ldots \ldots \ldots$

GENERAL APPROACH $\ldots \ldots \ldots \ldots \ldots \ldots \ldots \ldots \ldots \ldots \ldots \ldots \ldots \ldots \ldots$

PROJECT COMPONENTS $\ldots \ldots \ldots \ldots \ldots \ldots \ldots \ldots \ldots \ldots \ldots \ldots$

Traffic Trifecta Program Introduction ................... 13

"Home Safe for the Holidays." ....................... 14

Speeding / Child Passenger Safery / Seatbelts ................ 15

Speeding / Youthful DWI Offenses .................... 16

4 - PROJECT EVALUATION $\ldots \ldots \ldots \ldots \ldots \ldots \ldots \ldots \ldots \ldots \ldots \ldots \ldots$

OVERVIEW ................................. 17

DATA AND DATA COLLECTION ................... 18

Awareness, Perceived Risk of Enforcement, and Self-Reported Behavior . 18

Measured Speed ............................... 18

Seatbelt Usage Observations $\ldots \ldots \ldots \ldots \ldots \ldots \ldots \ldots \ldots \ldots 20$

Accident Analysis ............................. 21

EVALUATION RESULTS $\ldots \ldots \ldots \ldots \ldots \ldots \ldots \ldots \ldots \ldots \ldots . \ldots \ldots$

Enforcement Activity ........................ 21

PI\&E Activity .......................... 22

Awareness, Perceived Risk of Enforcement, and Self-Reported Behavior . 24

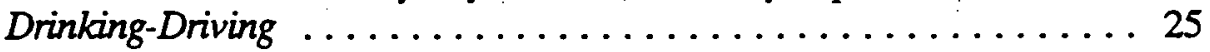

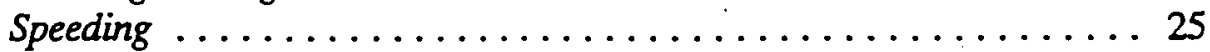

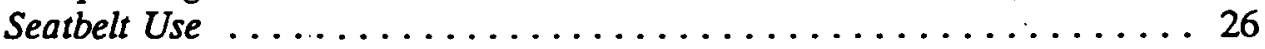




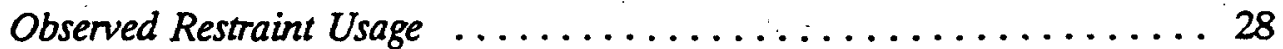

Accidents ................................ 28

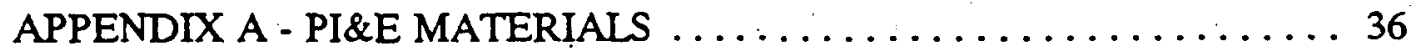

APPENDIX B - DRIVER SURVEY QUESTIONNAIRE . . . . . . . . 39

APPENDIX C - ANALYSIS OF ACCIDENT DATA ........... 41

PRELIMINARY EXAMINATION OF THE ACCIDENT DATA . . . . 42

ACCIDENTS REPORTED TO INVOLVE SPEED $\ldots \ldots \ldots \ldots \ldots \ldots .42$

ACCIDENTS REPORTED TO INVOLVE ALCOHOL . . . . . . . . . 42

MODELING PROXIES OF ALCOHOL-RELATED ACCIDENTS . . . . 45

REVIEW OF RESIDUALS $\ldots \ldots \ldots \ldots \ldots \ldots \ldots \ldots \ldots \ldots \ldots$

ARIMA MODELS ....................... 48 


\section{FIGURES}

Figure 1: DWI Arrests in Wichita and Topeka, January, 1988 - August, 1992 . 23

Figure 2: Speeding Citations in Wichita and Topeka, January, 1988 - August,

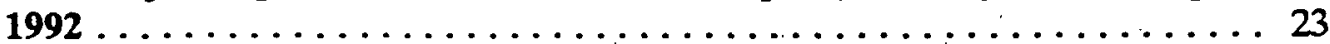

Figure 3: Seatbelt Citations in Wichita and Topeka, January, 1988 - August,

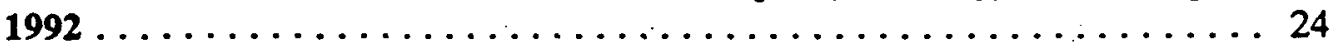

Figure 4: Change in Percentage of Drivers Exceeding the Speed Limit by at Least $10 \mathrm{mph}$ in Wichita and Topeka, April, 1991 - July, 1992 . . . . . . . 29

Figure 5: Change in Percentage of Seatbelt Users, April, 1991 - July, 1992 . . . 29

Figure 6: Nighttime Single Vehicle Accidents in Wichita, Topeka as a Control 31

Figure 7: Nighttime Single Vehicle Injury Accidents in Wichita, Topeka as a

Control .............................. 31

Figure C-1: All Accidents in Wichita and Topeka, January, 1988 to June,

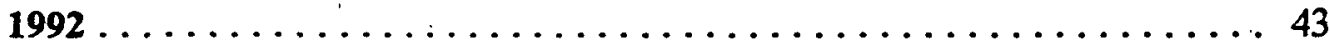

Figure C-2: Police-Reported Alcohol-Involved Accidents in Wichita and Topeka, January, 1988 to June, $1992 \ldots \ldots \ldots \ldots \ldots \ldots \ldots \ldots \ldots \ldots$. . . . . . . 43

Figure C-3: Nighttime Single-Vehicle Injury Accidents in Wichita and Topeka, January, 1988 to June, $1992 \ldots \ldots \ldots \ldots \ldots \ldots \ldots \ldots \ldots . \ldots . \ldots . \ldots 44$

Figure C-4: Police-Reported Speeding-Involved Accidents in Wichita and Topeka, January, 1988 to June, $1992 \ldots \ldots \ldots \ldots \ldots \ldots \ldots \ldots \ldots . \ldots 44$

Figure C-5: Cyclical Model of Nighttime Accidents in Wichita . . . . . . . . 48

Figure C-6: Nighttime Accidents in Wichita, Topeka as a Control . . . . . . 49

Figure C-7: Nighttime Injury Accidents in Wichita, Topeka as a Control . . . 50

Figure C-8: Nighttime Single Vehicle Accidents in Wichita, Topeka as a Control ............................ 50

Figure C-9: Nighttime Single-Vehicle Injury Accidents in Wichita, Topeka as a Control 


\section{TABLES}

Table 1: Comparison of Site Characteristics Prior to Project Period (Circa 1989) ............................... 9

Table 2: Phasing of PI\&E Campaigns and Field Data Collection Activity . . . 19

Table 3: Sample Sizes of "Before" and "After" Surveys in Driver License

Stations in Wichita and Topeka . . . . . . . . . . . . . . . 24

Table 4: Summary of Analysis of Driver Survey . . . . . . . . . . . . . 27

Table 5: Summary of Results of ARIMA Analyses of Proxies of Alcohol-Related

Accidents in Wichita ........................ 30

Table 6: Summary of Project Activity and Outcome ... . . . . . . . 33

Table C-1: Summary of Results of ARIMA Analyses of Proxies of Alcohol-

Related Accidents in Wichita $\ldots \ldots \ldots \ldots \ldots \ldots \ldots \ldots \ldots \ldots \ldots$ 


\section{EXECUTIVE SUMMARY}

This report describes the implementation and evaluation of a project in Wichita, Kansas, to test the hypothesis that combined speed, alcohol, and seatbelt enforcement strategies, coupled with a strong PI\&E program, can reduce the incidence of speeding, alcohol-impaired driving, and non-use of seatbelts. This project publicized the enforcement of several highway safety laws in combination, rather than enforcement of one particular law. This approach was designed to make enforcement more efficient in raising perceived risk of arrest for each type of violation and also to achieve increased deterrence by creating a perception of more severe penalties for multiple violations occurring in a single incident. We hypothesized that, as a result, deterrence for one category of violation may be enhanced by the perceived severity of sanctions for another.

The Wichita program was designed to sequentially emphasize five different combined enforcement strategies during a period of approximately one year. A PI\&E campaign focusing on each strategy was to operate for about two months. A general program theme was established for all of these campaigns, stressing the concept of simultaneous enforcement of speeding, DWI, and occupant restraint laws. The theme selected by the Wichita Police Department was:

Traffic Trifecta: Buckle Up - Slow Down - Drive Sober. Don't gamble with a life!

The themes of the five campaigns were:

\section{Traffic Trifecta Program Introduction}

2. "Home Safe. For The Holidays"

3. Speeding / Child Passenger Safety / Seatbelts

4. Speeding / Youthful DWI Offenses

\section{Traffic Trifecta Concept}

Components of several strategies were repeated in other strategies. For example, checking for child restraint use actually began during the holiday season (second strategy) around shopping malls because the Wichita Police Department believes this is an important time to show enforcement. This component was repeated during National Child Passenger Safety Awareness Week in February (third strategy). Repeating several strategy components provided a feeling of continuity throughout the program and provided for the needs of the community. All three messages (buckle up, slow down, drive sober) were repeatedly mentioned and enforced. 
The evaluation effort was directed at measuring the effect of the combined enforcement / PI\&E program on:

- driver awareness of the program;

- driver perceptions of enforcement;

- driver self-reported behavior with respect to speeding, drinkingdriving, and seatbelt use;

- measured speed distributions and seatbelt use at several locations throughout the program period; and

- accidents and accident variables related to drinking-driving, speeding and seatbelt use.

A comparison site (Topeka, Kansas) was used to help recognize trends that could affect the test site and confound the effects of the program in the test site (Wichita, Kansas). The comparison site was chosen so as to match the test site as closely as possible except that it planned no special traffic law enforcement program.

The formal kickoff of the program occurred on September 26, 1991, and the program continued through July, 1992.

The city of Wichita and the Police Department experienced many unexpected problems immediately prior to and during the project period. Extensive abortion protests focused national attention on clinics in Wichita drawing police manpower and media coverage. In addition, Wichita experienced a surge in gang-related activities including drive-by shootings. Even the weather conspired against the project as several tornados touched down, and Wichita suffered the largest loss of property in local history in a severe hail storm. These events captured public attention and forced reallocation of police resources.

Nevertheless, our evaluation showed a significant increase in $D W I$ enforcement in Wichita that was accompanied by increased PI\&E activity. However, there was no change in awareness of project messages related to DWI or to the combined enforcement program, nor was there any change in self-reported frequency of drinkingdriving. On the other hand, there was some evidence that perceived risk of DWI enforcement increased in Wichita, and several proxies of accidents involving alcohol were compatible with a program effect on DWI. These proxies declined some $20 \%$ to $35 \%$ during the Wichita project.

With respect to speeding, enforcement activity in Wichita actually decreased even though there was an increase in PI\&E activity. Thus, we would not expect any positive changes in outcome, and in fact, none was found. Likewise, there were also no positive changes in Wichita with respect to the outcome of the seatbelt component of the combined enforcement program, even though there were moderate increases in both enforcement and PI\&E activity.

Thus, in Wichita, circumstances beyond the control of the project prevented a fair test of the combined enforcement concept. The speeding enforcement effort and, to some extent; the seatbelt enforcement effort were neutralized by the transfer of 
resources and command emphasis to other, non-traffic enforcement activities. The program's apparent effect on DWI could plausibly be attributed to the maintenance of - a significant DWI enforcement threat supported by PI\&E during the project period. Conceivably, increased enforcement of speeding and seatbelt violations might also have shown a positive effect had the Wichita Police Department been able to maintain the level of enforcement activity initially planned.

The major conclusions of the Wichita field test are:

With respect to DWI

- Wichita's combined-enforcement program was more effective against alcoholrelated crashes than its prior enforcement program.

- Wichita's combined-enforcement program was more effective against alcoholrelated crashes than Topeka's nominal enforcement program.

Wuth respect to speeding and seatbelt use

- Wichita's combined-enforcement program was neither less effective nor more effective than its prior enforcement program.

- Wichita's combined-enforcement program was neither less effective nor more effective than Topeka's nominal enforcement program;

The Wichita project was based on a design concept requiring:

- use of high-intensity, combined-enforcement strategies incorporating both new and traditional techniques; and

- heavy use of public information and education tailored to match each of the combined-enforcement strategies.

As implemented, Wichita's combined-enforcement effort against DWI involved a significant increase in enforcement intensity (as measured by number of citations and number of officers assigned to enforce the target violation), but the enforcement intensity against the other two target violations either decreased or increased only moderately. Also, while the project did include a comprehensive PI\&E campaign, the phasing of that campaign did not always coincide with the phasing of the various combined enforcement strategies. Therefore, the basic requirements of the combinedenforcement concept were only partially met in Wichita. The effort against the one target violation that did meet most of the requirements of the project (DWI) resulted in reductions in proxies of alcohol-related crashes of at least $20 \%$. 
Thus, the results of the program suggest that an enforcement / PI\&E campaign that stresses more than one target violation can be effective against at least one of those violations. Whether it can also be effective against more than one violation remains to be determined, but research indicates that a crucial condition for multiviolation effectiveness is significantly increased enforcement of all of the target violations. Because of extraordinary demands on police resources that arose during the project, that condition was clearly not met in Wichita despite a good PI\&E effort. 


\section{1 - INTRODUCTION}

\section{GENERAL NATURE OF THE PROJECT}

This report describes the implementation and evaluation of a subproject in Wichita, Kansas, to determine whether combined speed, alcohol, and seatbelt enforcement strategies, coupled with a strong public information and education (PI\&E) program, can reduce the incidence of speeding, alcohol-impaired driving, and non-use of seatbelts. The project was conducted for the National Highway Traffic Safety Administration under Contract Number DTNH22-89-R-07396 entitled "Field Test of Combined Speed, Alcohol, Safety Belt Enforcement Strategies." This project publicized the enforcement of several highway safety laws in combination, rather than enforcement of one particular law. This approach was designed to make enforcement more efficient in raising perceived risk of arrest for each type of violation and also to achieve increased deterrence by creating a perception of more severe penalties for multiple violations occurring in a single incident. As a result, deterrence for one category of violation may be enhanced by the perceived severity of sanctions for another.

For example, a strategy may involve publicizing that all nighttime speeding stops will also include administration of a Preliminary Breath Test (PBT) for alcohol impairment (subject to probable cause constraints) and investigation of safety belt and child restraint use. Deterrence may be enhanced for the restraint and alcohol laws by an increased perception of the risk of arrest brought about by increased nighttime speeding enforcement. For the speeding violation, publicizing the enforcement itself may increase the perceived risk of arrest and also the perceived severity of punishment by the threat of a possible alcohol violation and its attendant sanctions.

This concept is also being tested in two other sites. in this contract, Knoxville, Tennessee and Lexington, Kentucky. The results of these two subprojects are documented in separate reports.

\section{PROJECT SCOPE AND APPROACH}

Each of the three subprojects (Knoxville, Lexington, and Wichita) was based on a design concept requiring:

1. use of high-intensity, combined-enforcement strategies incorporating both new and traditional techniques: and

2. heavy use of public information and education tailored to match each of the enforcement strategies.

Two distinct types of effort were required in each of the subprojects, (1) design and implementation of the Public Information \& Enforcement (PI\&E) program, and (2) evaluation of that program. The design and implementation effort began with the selection of suitable 
jurisdictions in which to locate the subprojects. This involved contact with NHTSA's regional offices as well as drawing upon our own knowledge of traffic enforcement agencies throughout the country. Once a list of possible jurisdictions and agencies was developed, we set about contacting management staff in those agencies. Initially, the contacts were by telephone and through written correspondence. We then visited agencies that appeared promising to confirm their appropriateness. Criteria used in selecting sites are discussed later in this report and included those critical to enforcement and those critical to the PI\&E effort. Wichita was the third site selected. The Wichita subproject began in September 1991, and was completed in July, 1992.

The evaluation effort was directed at measuring the effect of the enforcement / PI\&E program on the following groups of variables:

- driver awareness of the program;

- driver perceptions of enforcement;

- driver self-reported behavior with respect to speeding, drinkingdriving, and seatbelt use;

- measured speed distributions and seatbelt use at several locations throughout the program period; and

- accidents and accident variables related to drinking-driving, speeding and seatbelt use.

The evaluation was designed to measure changes in these variables in the test site over the project period. In addition, a comparison site was sought to help recognize trends that could affect the test site and confound the effects of the program in the test site. The comparison site was chosen so as to match the test site as closely as possible, except that it planned no special traffic law enforcement program during the project period. This design would permit one to estimate the effectiveness of the combined enforcement effort relative to a nominal enforcement effort involving no special campaign of any kind.

In addition, we contacted highway safety practitioners and surveyed the literature to learn whether there had been any evaluations of single-strategy speed enforcement programs in jurisdictions similar to our test jurisdictions. If such data were available, it could be combined with the data from our pertinent site pairs to get an estimate of the benefit of a combined enforcement approach compared to a single-violation enforcement approach.

No literature was found reporting the jurisdiction-wide effects of such a campaign on speed distributions or traffic crashes. Prior research on speed-enforcement campaigns appears to have focussed on their effects in the immediate vicinity of an enforcement symbol rather than within the entire jurisdiction served by an enforcement agency. However, a comparison site, Chattanooga, Tennessee, used in this project for the Knoxville, Tennessee test site did implement a single-strategy speed 
enforcement program in which the groups of variables listed above were quantified by our project team. The data (discussed at length in a companion site report) strongly suggest that the Chattanooga program was more effective against speeding and related crashes than was its prior nominal enforcement program, and that the program achieved its positive effects against speeding with no apparent negative effects on perceived enforcement or self-reported behavior with respect to DWI or seatbelt use. There were also no negative effects on observed use of seatbelts. These findings were more meaningful in the context of the Knoxville field test than in the context of the field test reported in this report and are therefore not discussed further in this report.

Ultimately, we selected Topeka, Kansas, as the comparison site for the third test site, Wichita, Kansas. The criteria discussed in the next chapter were used in selecting Wichita and Topeka. 


\section{2 - PROJECT SITES}

\section{SITE SELECTION}

Our contract called for sites with populations between 200,000 and 500,000 . Two categories of criteria were used in selecting sites of this size, those critical to enforcement and those critical to the PI\&E effort. Site selection criteria critical to enforcement included:

Willingness of police to cooperate. This criterion included the willingness to adhere to the experimental design (discussed later in this report), and the willingness to provide personnel and equipment needed for the enforcement efforts.

Conditions justifying speed enforcement. This criterion was aimed at ensuring that traffic laws, speed limits, and road conditions were such that a program that includes speed enforcement had a reasonable chance of influencing driver behavior.

Availability of data. This included specific data on the coincidence of problem behaviors (e.g., speeding and DWI) in the locality, for the purpose of planning the enforcement campaign. It also included the availability of more general data (accident, arrest, etc.) for determination of program effectiveness. It included the current availability (or reliable prospect of future availability) of independent attitudinal survey data on issues related to the project.

Quality and accessibility of accident data. Computer tapes from a central agency were preferable to hard copy from the local agencies, which would have to be retrieved and keypunched. The detail of information on the accident reports was also important; for example, data which contained the TAD scale for vehicle damage were deemed preferable to those which did not. Also, sites with more extensive police investigation of accidents were preferable to those which relied more heavily on operator reports.

Legal environment. Considerations were the requirements for a speeding citation, the definitions of the various levels of alcohol offenses, the legal techniques for determining BAC, whether roadblocks were permitted, the exact requirements for safety belt use, and the strategies permitted for enforcing safety belt use. It was also important that there would be no new local or state legislation which would affect the legal basis for the enforcement strategies (e.g., repeal of a seatbelt law, or drastic strengthening of the drunk driving laws).

Availability of Comparison Sites. Comparison sites were preferably from the same states. Confounding factors, especially those arising from differences in laws, and in accident data, can make a comparison of sites in different states more difficult. Desirable characteristics of comparison sites were: 
- Similarity in general social and economic characteristics.

- Similarity in general characteristics of the Highway Transportation System.

- Similarity in intensity of enforcement of target traffic law violations.

- Similarity in historic traffic law enforcement patterns and țends.

- No plans for changes, in current traffic law enforcement and PI\&E practices.

- Similarity in historic accident patterns and trends.

- Data availability comparable to those of the test sites.

- Willingness to permit collection of speed and seatbelt use data.

Site Selection Criteria Critical to the PI\&E Campaign were:

Willingness of local police agencies to make true commitment to the program. This included the willingness on the part of the chief(s) to give the project high priority, to make resources available to make this a real and permanent initiative, and to take an active role in both the enforcement and public information activities.

Availability of an effective police-based local coordinator. The potential for success for this type of public information program can rest largely on the effectiveness of the local coordinator. The ability to work well with the public, the media, and the departments cooperating in the program was essential. A person based within the enforcement agency was desired.

Ability to develop widespread local ownership and resources. This project had few funds available for materials and promotions because the development of a program that could be operated locally without federal funding was desired. It was therefore necessary to choose a site that had sufficient resources available to supplement the efforts of the law enforcement agencies. These resources included support of local businesses, industry and volunteer and civic groups.

Availability of local media. Local television and radio stations, newspapers and other media outlets were necessary to get the messages out to a significant portion of the driving public. Ideally, the site would be its own media market or the main metropolitan area within the market. The support of the media in donating public service efforts to the program, including the development, production and play of public service announcements was an essential ingredient.

The suitability of Wichita as a test site and of Topeka as a comparison site with respect to these criteria was assessed and documented in an interim report to NHTSA. This site pair was recommended in the report, and the recommendation was accepted by NHTSA.

\section{TEST SITE DESCRIPTION}

Wichita is located in south central Kansas and had a population of 289,000 in 1986. Population remained relatively stable in the 1980 s with about $3 \%$. growth in the 
1980-1986 period projected. The current population is estimated at 300,000 . The city is spread over an area of 188 square miles. Seven square miles have been added since 1982 through annexation. Aircraft manufacturing is the prominent industry. Two interstate highways pass through the city, I-235 and the Kansas Turnpike.

The major traffic law enforcement agency in the city is the Wichita Police Department (WPD), although the Kansas Highway Patrol and the Sedgwick county Sheriffs Department enforce traffic laws on the interstate highway segments lying within the city limits.

The WPD had 435 sworn officers and 155 civilian employees in 1989. In addition to the chief, there are three deputy chiefs, one for each of the three bureaus of the department. The bureaus are Field Services, Investigations, and Support Services. Field Services contains the two patrol divisions (called Patrol West and Patrol East) and the Special Operations Division, and has the largest staff of the three bureaus. Each division is headed by a major, and these three majors are the only majors in the department.

Traffic law enforcement is performed primarily by the Special Operations Division's Traffic Section. The Division had 43 sworn officers and 40 civilians in 1989. Officers are assigned specifically to motorcycles or radar cars. Motorcycles are used extensively, and there are currently 32 motorcycles compared to 16 radar cars being used by the Traffic Section. Motorcycle officers are assigned to cars in bad weather. Uniformed civilian personnel are responsible for accident investigation and parking enforcement. The Division also has a special DWI unit that operates Breath Alcohol Testing Vans (BAT Vans) that perform breath alcohol tests and assist in processing drivers arrested for DWI.

In 1989; the WPD made 1,680 arrests for DWI and issued 102,226 citations for moving traffic violations, including 52,695 citations for speeding. The per capita arrest rate for DWI was $0.56 \%$ in 1989 , about twice that of the state as a whole, but still below the median for the U.S. (about 1.08\% in 1987). The DWI arrest rate was extremely low prior to 1982 (about $0.16 \%$ ) when the city started receiving 402 funds to beef up its DWI enforcement. The rate has remained relatively stable over the past several years. Speeding citations are about average for a jurisdiction of this size and were also stable prior to implementation of the combined enforcement program.

Traffic accidents in Sedgwick County (Wichita) totaled 11,278 in 1989 and have been stable. There were 4,296 injury accidents in 1989.

\section{COMPARISON SITE DESCRIPTION}

Topeka is located in northeastern Kansas and had a population of 119,000 in 1986. This figure remained stable throughout the 1980s. The current population of the city of Topeka is estimated at 119,883 and when combined with Shawnee County increases to 160,000 . Topeka is the capitol of Kansas which means the government 
is the major employer. The city covers 57 square miles. Three interstate highways pass through the city, I-70, I-470 and I-335.

The major traffic law enforcement agency in the city is the Topeka Police Department which has 250 sworn officers and 110 civilians. The department is headed by a chief and one assistant chief. Five majors head the five divisions within the department: Traffic, Patrol, Services, Detectives and Communications. There are 40 radar cars in operation and several motorcycles. Although there is no special DWI dedicated unit or testing vans, car units are used to target DWIs.

In 1990, the TPD made 1,387 arrests for DWI and issued 13,642 citations for speeding. These numbers have fluctuated very little over the past several years. Traffic accidents in Shawnee County (Topeka) totaled 52,695 in 1989 and have been stable. There were 4,296 injury accidents in 1989.

\section{SUMMARY OF CHARACTERISTICS OF THE TEST SITE AND THE COMPARISON SITE}

Table 1 compares the counties in which the two sites were located with respect to key site selection criteria and some other pertinent variables. The table indicates that the sites compared very well on all of the characteristics shown, although Topeka is somewhat smaller than Wichita. 
Table 1: Comparison of Site Characteristics Prior to Project Period (Circa 1989)

\begin{tabular}{|c|c|c|}
\hline Characteristic & Wichita & Topeks \\
\hline State located in & Kansas & Kansas \\
\hline $\begin{array}{l}\text { Geographical area, } \\
\text { square miles }\end{array}$ & 188 & 57 \\
\hline $\begin{array}{l}\text { General social and eco- } \\
\text { nomic characteristics }\end{array}$ & $\begin{array}{l}\text { Population: } 298,000 \\
x<25 \text { yrs: } 37.5 \\
x>65 \text { yrs: } 11.4 \\
\text { Per capita income: } 17,727 \\
\text { Unemployment: } 4.4 \%\end{array}$ & $\begin{array}{l}\text { Population: } 143,000 \\
x<25 \text { yrs: } 35.1 \\
\dot{x}>65 \text { yrs: } 13.1 \\
\text { Per capita income: } 17,886 \\
\text { Unemployment: } 4.2 \%\end{array}$ \\
\hline $\begin{array}{l}\text { Righway Transportation } \\
\text { System }\end{array}$ & $\begin{array}{l}\text { Registered vehicles: } 371,561 \\
\text { Road mileage by type: } \\
\text { State highway: } 194 \\
\text { County roads: } 1,740 \\
\text { City streets: } 1,540\end{array}$ & $\begin{array}{l}\text { Registered vehicles: } 140,290 \\
\text { Road mileage by type: } \\
\text { State highway: } 125 \\
\text { County roads: } 1.007 \\
\text { City streets: } 608 \\
\end{array}$ \\
\hline $\begin{array}{l}\text { Historic accident pat- } \\
\text { terns and trends }\end{array}$ & Stable & Stable \\
\hline $\begin{array}{l}\text { Intensity of traffic en- } \\
\text { forcement }\end{array}$ & Moderate & Average \\
\hline Speeding citations & 52,695 & 13,642 \\
\hline DWI arrests & 1,680 & 1,387 \\
\hline $\begin{array}{l}\text { Historic enforcenent } \\
\text { potterns and trends }\end{array}$ & Stable & Stable \\
\hline Dota availability & $\begin{array}{l}\text { Enforcement data available } \\
\text { from pol ice agencies; acci- } \\
\text { dent data and survey data } \\
\text { from state. }\end{array}$ & $\begin{array}{l}\text { Enforcement data available } \\
\text { from police agencies; acci- } \\
\text { dent data and survey data } \\
\text { from state. }\end{array}$ \\
\hline $\begin{array}{l}\text { Permission to collect } \\
\text { speed and seatbelt use } \\
\text { data }\end{array}$ & Permission given & Permission given \\
\hline
\end{tabular}


Page 11

\section{3 - PROJECT DESCRIPTION}

This chapter describes the local project, the strategies employed, and the general time frame. The description is in narrative form and does not include quantitative measures of activity which are provided in the Chapter 4, PROJECT EVALUATION.

This project was operated as a local project housed within the Wichita Police Department. The development and operation of enforcement and PI\&E strategies were local efforts. Local activities were coordinated for WPD by Lt. Ronald $R$. Harris under the direction of Major K. Tyler Brewer. Mid-America's role was to provide assistance as required in the design of the project and in the development of PI\&E materials. The University of North Carolina Highway Safety Research Center participated as a subcontractor to Mid-America with responsibility for assisting in the PI\&E effort. Significant local effort was put forth in coordinating the project and in producing PI\&E materials.

\section{GENERAL APPROACH}

A general program theme was chosen for the project stressing the concept of simultaneous enforcement of DWI, speeding, and occupant restraint laws. The theme selected by the Wichita Police Department was:

\section{Traffic Trifecta: Buckle Up - Slow Down - Driver Sober. Don't gamble with a life!}

The image for the Traffic Trifecta concept was a triangle composed of three graphics, a Wichita police cruiser, breath-alcohol testing (BAT) van and motorcycle officer. Anyone stopped for speeding would automatically be observed for belt use and driving under the influence. The message was that each stop would actually be three enforcement stops in one. To give the program continuity and high recognition, a form of the theme was used on all materials and PSAs produced.

Five different combined enforcement strategies were planned for a period of approximately one year. However, the initial plans had to be modified. The city of Wichita and the Police Department experienced many unexpected problems immediately prior to and during the project period. Extensive abortion protests focused national attention on clinics in Wichita drawing police manpower and media coverage. As a result, the project kick-off scheduled for July, 1991, was delayed. As of September 3, 1991, the Wichita Police Department returned to normal operations, and so the kick-off news conference was held September 26, 1991. However, during the life of the project; the abortion protestors and supporters returned to clash on several occasions. In addition, Wichita experienced a surge in gang related activities including drive-by shootings. During these times the media chose to overlook the traffic safety program. The weather also drew the public's attention as several tornados touched down and Wichita suffered the largest loss of property in local history (\$570 million in insurance claims) due to a massive hail storm on June 19 , 
1992. Many police cruisers were totaled or severely damaged, again straining resources.

Unfortunately, significant police resources had to be re-allocated in the Spring of 1992, effectively putting an end to the enforcement component of the project. However, new PSAs were produced and enforcement levels rose again during the summer months.

Despite all the distractions, most of the enforcement strategies during this 10month period were conducted with accompanying TV, radio; and newspaper coverage. Billboards were on display for the entire program, brochures were passed out to the public, television PSAs were aired and public speaking engagements were made by the police officers.

The brochure was developed to explain the Traffic Trifecta program. This brochure was also designed to hold the citations given out for violations. A total of 18,000 brochures were handed out to traffic violation offenders and the general public over the life of the Traffic Trifecta project.

\section{STRATEGIES}

The five strategies initially planned were:

\section{Traffic Trifecta Program Introduction}

2. "Home Safe For The Holidays" .

\section{Speeding / Child Passenger Safety / Seatbelts}

\section{Speeding / Youthful DWI Offenses}

\section{Traffic Trifecta Concept}

Components of several strategies were repeated in other strategies. For example, checking for child restraint use actually began during the holiday season (second strategy) around shopping malls because the Wichita Police Department believes this is an important time to show enforcement. This component was repeated during National Child Passenger Safety Awareness Week in February (third strategy). Repeating several strategy components provided a feeling of continuity throughout the program and provided for the needs of the community. All three messages (buckle up, slow down, drive sober) were repeatedly mentioned and enforced. Descriptions of the five strategies follow. 


\section{PROJECT COMPONENTS}

\section{Traffic Trifecta Program Introduction}

A kick-off news conference was held on Thursday, September 26. The Traffic Trifecta project was introduced by Major Brewer and Lieutenant Harris. They announced that as part of the Traffic Trifecta Program, anyone stopped for speeding would also be checked for impaired driving and seatbelt use. Sobriety checklanes were described at the news conference as one of the enforcement strategies. A sobriety checklane was conducted as part of the kick-off and the media was invited to attend. Two television stations provided coverage during the evening newscasts. Channel 10 (KAKE) used the program as their lead story on the Thursday, September 26, evening newscast and Channel 3 (KSNW) also covered the kick-off announcement. The Wichita Eagle ran an article in the September 27 edition.

The public information and enforcement program also kicked off in September with two television public service announcements (PSAs) augmented with billboard coverage and handouts. (Copies of billboards, the brochure and storyboards for the television PSAs are included in the Appendix.) The following publicity was used:

- TV PSAs - Two TV public service announcements were produced by KSNW, Channel 3 in Wichita and were aired during this phase of the program. One PSA focused on explaining the Traffic Trifecta Program; the second PSA emphasized the use of sobriety checklanes and how drinking drivers could not avoid detection.

- Billboards - Billboards announcing Traffic Trifecta as the safest bet in town were displayed at five locations throughout the city. The slogan "Don't Gamble With Your Life - Drive Sober, Slow Down and Buckle Up" was used.

- Handout - A brochure was developed that explained the Traffic Trifecta program. These brochures were given out to motorists passing through the checklanes and were used as jackets for citations given for violations. One traffic officer handed out brochures to parents dropping off children at an elementary school.

A sobriety checklane and saturation patrols were conducted as part of the lead strategy in an attempt to gain high visibility with the media and driving public. A checklane was thought to strengthen the program's initial exposure at a time when establishing the program identity was critical. Saturation patrols give high visibility of law enforcement in areas identified as high risk locations.

A team of officers from the dedicated DWI unit manned the checkpoint that was conducted the day after the kick-off news conference. A mobile breath-alcohol testing van ("BAT van") was used to support the checklane team. The checklane was operated in accordance with court-approved guidelines. Officers stopped all vehicles 
traveling west bound in the 7100 block of East Harry (a main, four lane thoroughfare running through Wichita). Three hundred and seventy-three (373) vehicles were processed through the checklane from 11:00 p.m. - 1:00 a.m. The roadblock was designated by signs and patrol cars with lights flashing, and an approximate location was publicized in the media. All drivers were asked to provide a driver's license, vehicle registration and proof of insurance. Officers noted the use of seatbelts and engaged the drivers in a conversation during which the drivers were observed for signs of intoxication. Conversations with drivers lasted an average of 1.87 minutes. Kansas law does not allow a vehicle to be detained for more than three minutes. All drivers passing through the checkpoint were given the Traffic Trifecta brochure.

Drivers and occupants not wearing seatbelts were directed to buckle up, but wére not cited for that offense. Drivers without driver's licenses, vehicle registration, proof of insurance or who were initially thought to be intoxicated were directed into an adjacent parking lot. Seven drivers were evaluated; two were arrested on DWI charges and two were arrested for open container violations. Channel 3 (KSNW) sent out a cameraman to report on the roadblock. Major Brewer gave a statement concerning the Traffic Trifecta program, and the cameraman also recorded an arrest for suspected DWI. This footage was aired during the Saturday; September 28 KSNW newscast.

Radar was located upstream from the checklane. The radar component is used to increase the "hit ratio" in stopping drivers who are impaired relative to drivers who are not impaired. Speeding provides a reason for departing from the sampling scheme that is normally used, allowing the police to identify specific, higher-risk vehicles.

Routine saturation patrols were also conducted on a weekly basis by the dedicated DWI unit. Five to seven officers would patrol a designated area during the times when drinking drivers were more likely to be on the road and at locations where they were more likely to travel. Once a month, the dedicated unit was joined by the second detail of traffic officers. This cooperative patrol included 12 to 14 officers.

"Home Safe for the Holidays"

A holiday season strategy (Thanksgiving through New Years Eve) was developed to emphasize safe driving habits. "Home Safe For The Holidays" has been a holiday theme used by the Wichita Police in years past and so was incorporated into the Traffic Trifecta program. Emphasis was placed on how responsible driving habits (don't drink and drive, wear a seat belt and don't speed) and enforcement of the Traffic Trifecta program through dedicated Wichita police officers are the best protection motorists have to prevent traffic accidents.

The cooperative saturation patrol was conducted at the start of this strategy and received extensive media coverage. All three major TV stations (KWCH, KAKE and $\mathrm{KSNW}$ ) and one radio station (KFDI) ran news stories. 
Lieutenant Harris spoke about the Traffic Trifecta program and highway safety issues to employees of Foxmeyer, a local corporation, on December 11. Lieutenant Harris also appeared on the DWI Victim Panel of Witnesses sponsored by the YWCA in Wichita. Persons who are convicted or plead guilty to driving while drunk or drugged are required to attend the meeting. Victims and / or witnesses give testimony of experiences they or loved ones have endured, due to the actions of drunk or drugged drivers. The meetings convene once a month for approximately two hours. Local television newscasts covered the meeting and included remarks made by Lieutenant Harris regarding the Traffic Trifecta program. On January 16, Officer Steve Kenny conducted a demonstration for the Marine Corp during which two audience participants were asked to consume alcoholic beverages. The participants were then tested every 30 minutes. A "BAT van" was on display and an Intoxilyzer unit was used for testing the participants. Traffic Trifecta brochures were handed out and Officer Kenny explained the program.

In December, Lieutenant Harris invited a television news reporter from Channel 10 to ride along on a saturation patrol the night before Thanksgiving, a time when drinking drivers had been a problem in the past. An arrest was made for DWI and video footage aired on the 10 p.m. news and at noon on Thanksgiving day. The cooperative saturation patrols conducted in December also drew media coverage by all three major television stations and the Wichita Eagle newspaper.

As an additional enforcement part of this strategy, Wichita police officers monitored malls and shopping center exits for individuals transporting children under fourteen years of age without child safety devices. Enforcement was for thirty minute intervals at each of the designated sites on December 6 and December 13. Emphasis was placed on coupling enforcement of the adult belt law (secondary enforcement) with child restraint violations (primary enforcement). Officers stopped violators and handed out Traffic Trifecta pamphlets.

\section{Speeding / Child Passenger Safety / Seatbelts}

Though the Kansas adult seatbelt ordinance is a secondary enforcement measure, the child (age 13 years or less) restraint law is a primary enforcement law. The implementation of this strategy was timed to include National Child Passenger Safety Awareness Week in February, 1992. The local newspaper, the Wichita Eagle, ran an extensive article on child safety seats in the February 10th edition. Lieutenant Harris was interviewed by radio station KFDL. A local talk show ("Mike and Mogey") on Channel 12 in Wichita talked with EMS personnel about child safety seats. Lt. Don Deckert, Public Information Officer for the WPD gave a statement which aired on Channel 12 television news. Channel 12 also reported stepped up enforcement of seatbelt laws in Wichita and interviewed a Kansas Highway Patrol officer.

Speed enforcement activity focused on the weekly saturation patrols conducted by the dedicated DWI unit and once a month as a combined effort of the DWI unit and second detail traffic officers. 


\section{Speeding / Youthful DWI Offenses}

This strategy was scaled down due to a drain on available WPD manpower and equipment. However, during the month of April, enforcement of under age violators was conducted citywide. Nineteen of the 70 arrests made by the dedicated DWI unit were of persons under the age of 21. In addition, local SADD chapters started their own safe prom campaign and two PSAs were aired on KKRD radio during the month of May (one produced by SADD and one by the District Attorney). Also, Traffic Trifecta billboards were on display and the television PSA spots continued to keep. the project operative.

WPD stepped up saturation patrols during the time period when local proms were held. Regular saturation patrols continued, and officers were instructed to check for all Traffic Trifecta offenses. A sobriety checkpoint was conducted May 29, 1992 at 3200 South Broadway (a main thoroughfare) in Wichita from 9:30 p.m. to 12:30 a.m. with officers from the Wichita Police Department and the Kansas Highway Patrol. The checklane was designated by signs and patrol cars with lights flashing. Drivers were detained for an average of 1.36 minutes and brochures were distributed. Six drivers were evaluated resulting in two arrests for DWI. Four people were arrested for open container violations and six citations were written for not wearing seatbelts.

\section{Traffic Trifecta Concept}

The final strategy replayed the general campaign used to kick-off the project. Two ten second television PSAs were produced and aired during this time period. One PSA warned that drunk drivers cannot avoid DWI checkpoints. The second PSA cautioned motorists to avoid flashing lights and sirens by driving the speed limit.

Two new billboard messages also were produced and posted as part of this strategy. Both focused on speed. One reinforced the TV PSA on speeding with the message, "In Wichita, avoid flashing lights and sirens. Drive the Speed limit." The other read, "In Wichita, getting out of a speeding ticket is easy. Slow down."

Both the PSAs and billboards received extensive exposure during June and July. The newspaper covered DWI laws on June 16. 


\section{4 - PROJECT EVALUATION}

This chapter presents our evaluation of the Wichita combined enforcement project. The approach, methods, and results of the evaluation are described in detail.

\section{OVERVIEW}

As indicated in Chapter 1 of this report, the evaluation of this project was initially designed to compare various measures of effectiveness in the test site (Wichita) with those in a similar site (Topeka) that operated a "nominal" or "control" enforcement program against DWI, speeding, and non-use of seatbelts.

The evaluation was conducted on several levels. At the lowest level, project activity was monitored. Two types of activity were generated by this project: enforcement and PI\&E. The activity evaluation tracked and assessed the enforcement and PI\&E effort over the course of the project. The enforcement data consist primarily of arrests for DWI and citations for speeding and non-use of restraints. The PI\&E data include such measures of exposure as the number of plays of PSAs by given stations, and number of special events held.

Higher levels of project evaluation dealt with the effects of the project activities on variables related to the target driving behaviors, that is, DWI, speeding, and seatbelt use. Awareness, perceived risk of enforcement, and self-reported behavior were measured through questionnaires filled out by drivers at driver license stations. The awareness component was concerned both with awareness of project messages as disseminated through PI\&E activities, and with the awareness of the enhanced enforcement activity generated by the project. Perceived enforcement risk dealt with the drivers' perception of the risk of getting arrested or ticketed for one of the three target violations, and self-reported behavior addresses the drivers' own reports of violating DWI, speeding, and seatbelt-use laws. The survey was conducted in Wichita and Topeka in two periods, the first occurring shortly before the Wichita subproject began and the second shortly after the Wichita subproject was completed.

A field measurement program was conducted to obtain data on actual speeding and seatbelt-use behavior. Vehicle speeds were measured and seatbelt use was observed at several locations in Wichita and Topeka. Several waves of measurements were conducted.

Finally, an analysis of traffic accidents was performed for both sites. The analysis was concerned with the time variation of accidents and accident losses involving DWI, speeding, and non-use of seatbelts. Accident data were provided by the Kansas Department of Transportation, Office of Traffic Safety. 
Table 2 shows the phasing of the various PI\&E strategies and the data collection activity. As indicated in the prior chapter, the formal kickoff of the program occurred on September 26, 1991, and the program continued on through July, 1992.

A discussion of the data and data collection procedures used in the project is presented next. This is followed by the evaluation and by a synthesis and interpretation of the results of the evaluation.

\section{DATA AND DATA COLLECTION}

\section{Awareness, Perceived Risk of Enforcement, and Self-Reported Behavior}

The data for this level of evaluation were collected through a driver survey conducted at drivers license stations in Wichita and Topeka. Table 2 shows the time phasing of the two survey waves (as well as the time phasing of the field measurement program, discussed later) in relation to the five PI\&E campaigns. The instrument used in both jurisdictions is shown in Appendix B. Persons appearing at driver license stations were given the questionnaires to fill out while they were waiting to be served at the stations. Refusal rates were less than $1 \%$.

Questions 1 through 3 sought information on the respondents' reasons for being in the driver license station and their age and sex. Question 4 dealt with the respondents' awareness of public information messages relating to DWI, speeding, and seatbelt use, and question 5 asked about any perceived increase in the enforcement of DWI, speeding, and seatbelt use over the past three months. Question 6 asked about the respondents' drinking frequency, and question 7 asked about the respondents' frequency of drinking-driving. Questions 8 through 10 sought information about the respondents' self-reported driving behavior with respect to DWI, speeding, and seatbelt use. Questions 11 through 13 asked about any perceived increase in enforcement risk with respect to DWI, speeding, and seatbelt use over the past three months.

\section{Measured Speed}

Speed data for the entire project were collected according to the following experimental design: 
Table 2: Phasing of PI\&E Campaigns and Field Data Collection Activity

\begin{tabular}{|c|c|c|c|c|c|c|c|c|c|c|c|c|c|c|c|c|c|c|}
\hline \multirow{2}{*}{ Activity } & \multicolumn{18}{|c|}{ Month } \\
\hline & $\mid \begin{array}{ll}\text { Apr } \\
1991\end{array}$ & May & $\operatorname{Jun}$ & Jul & Aug & Sep & oct & Nov & oec & $\begin{array}{l}\text { Jan } \\
1992 \\
\end{array}$ & $\mathrm{Feb}$ & Mar. & Apr & May & Jun & Jut & Aug & Sep \\
\hline \multicolumn{19}{|l|}{ PIRE Campaigns } \\
\hline \multicolumn{19}{|c|}{$\begin{array}{l}\text { Campaign } 1 \text { - Iraffic } \\
\text { Irifecta Program Introduction }\end{array}$} \\
\hline \multicolumn{19}{|c|}{$\begin{array}{l}\text { Compaign } 2 \text { - Home Safe for } \\
\text { The Hol idays }\end{array}$} \\
\hline \multicolumn{19}{|c|}{$\begin{array}{l}\text { Campaign 3. Speeding / child } \\
\text { Passenger Safety / Seatbelts }\end{array}$} \\
\hline \multicolumn{19}{|c|}{$\begin{array}{l}\text { Campaign } 4 \text { - Speeding / } \\
\text { Youthful oUI Offenses }\end{array}$} \\
\hline \multicolumn{19}{|c|}{$\begin{array}{l}\text { Campaign } 5 \text { - Iraffic Trifecta } \\
\text { Concept }\end{array}$} \\
\hline \multicolumn{19}{|l|}{ Data Collection } \\
\hline \multicolumn{19}{|l|}{ Attitude Survey } \\
\hline Field Measurements & 1 & & 1 & & & & 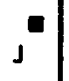 & & & & & & & & & & & \\
\hline
\end{tabular}

Notes:
1. Wichita
2. JJJS Topeka 
- Observations at each city were made five times during the project. Each of these sets of observations was called a "wave." The first wave was before the project to provide "baseline" data, the last after completion of the project. In Wichita, two waves were conducted before the formal kickoff of the project, a third wave was conducted before the half way point and a fourth wave was conducted after the project was formally completed.

- In each city, observations were made at eight différent locations. In Wichita, one location had to be replaced during the project because of road construction.

- Observations were made during three time periods called "shifts:" 1 pm - 3 $\mathrm{pm}, 6 \mathrm{pm}-8 \mathrm{pm}$, and $8 \mathrm{pm}-10 \mathrm{pm}$. The design was balanced, so that all combinations of waves, locations, and shifts were covered.

During data collection, measurements of individual vehicle speeds were obtained, together with the lane used by the vehicle, and the vehicle type. In addition, vehicle counts for five minute periods were made to get information on traffic density. The locations were chosen to represent the range of different speed limits at the site, and were also locations where speeding was recognized by the local police as a problem. In addition, the locations were such that an observation vehicle could be safely parked without being obtrusive or affecting speeds. Following these general principles, our subcontractor, The Center for Applied Research (CAR), selected the specific locations on the basis of information provided by the local police. Speed measurements were made with modified radar guns which operated on a frequency which did not trigger radar detectors, and which could be used unobtrusively.

\section{Seatbelt Usage Observations}

Seatbelt usage was obsierved at the roadside by the same field team that collected the speed data. Seatbelt observations were made in 24 sessions during each of the seven waves. The eight observation locations were at controlled intersections, where vehicles had to stop. Intersections were selected by CAR to represent a wide range of speed limits and other conditions.

Observations were made during the time period $3 \mathrm{pm}-6 \mathrm{pm}$, when no speed measurements were made. Sessions at each location were held on three different days of the week, but no attempt was made to assign them to a specific time within each three-hour period.

Observations were made by observers looking into the vehicles and observing shoulder-belt and child restraint use for the driver and one front-seat passenger. Vehicle type, driver sex, driver shoulder belt use were recorded in four classes. If a front passenger seat was occupied, passenger sex and shoulder belt-use were recorded in the same categories used for the driver. In addition, seat use by a child, seat use by a child under four years of age, and any child held by the passenger were recorded. 


\section{Accident Analysis}

Accident data were taken from computerized files of police accident reports. The data covered the period starting January 1, 1988, and ending June 30, 1992. The files contained data on non-pedestrian accidents from Sedgwick County (Wichita) and Shawnee County (Topeka). Using computer tapes provided by the Kansas Department of Transportation, Mid-America staff developed monthly counts of various kinds of accidents and accident-related events. Variables reflecting these counts were:

Total number of accidents

Number of injury accidents

Number of property damage accidents

Number of nighttime accidents

Number of daytime accidents

Number of occupants with injuries of any kind

Number of nighttime injury accidents

Number of daytime injury accidents

Number of nighttime property damage accidents

Number of daytime property damage accidents

Number of alcohol-related accidents (police-reported)

Number of single-vehicle accidents

Number of nighttime single-vehicle accidents

Number of injury single-vehicle accidents

Number of nighttime single-vehicle injury accidents

Number of occupants not injured

Number of occupants with minor injuries

Number of occupants with serious or fatal injuries

Number of speeding-related accidents (police-reported)

\section{EVALUATION RESULTS}

\section{Enforcement Activity}

The primary available quantitative measures of overall enforcement activity were DWI arrests, speeding citations, and citations issued for non-use of restraints. In Wichita, monthly counts of DWI arrests, non-use of seatbelts and speeding citations were available for the project period as well as for 1990 and the remaining months of 1991 prior to the start of the project.

$D W I$ arrests in Wichita showed a rapid increase after the program start, while there was an overall declining trend in Topeka (Figure 1). The total number of DWI arrests in Wichita during the first seven months of the program period was 1,526 , a $20 \%$ increase over the preceding seven months, and $19 \%$. over the same period one year earlier. With a standard deviation of the total for this period of $4 \%$, the increases are so large that they are almost certainly not the result of chance fluctuations in enforcement. After April 1992, arrests declined sharply to a level about equal to their pre-program mean, and then began to rise slowly again. 
Before the start of the program, speeding citations in Wichita fluctuated, with a weak declining trend. Citations levelled off during the program, but at a lower level than before (Figure 2). During the first seven months of the program, there were 20,952 speeding citations, which was $6 \%$ less than during the seven months immediately preceding the program, and $19 \%$ less than the same seven months one year earlier. However, the number of citations varied considerably from month to month. Based on this variation during the seven months one year earlier (corrected for the varying lengths of the months), the standard deviation of a seven-month total is $10 \%$. Thus the reduction during the first seven months of the Traffic Trifecta program could be due to the random variations of enforcement, except that visual inspection suggests that it could be part of a trend. Again, citations dropped sharply in the Spring of 1992, reflecting the reallocation of police resources noted in the prior chapter. In Topeka, there was a slight increasing trend in speeding citations before the start of the program in Wichita, and a big drop about the time the program started, followed by a slight recovery, but to a lower level than before.

Seatbelt citations showed an increasing trend in Wichita. During the first seven months of the project, they reached their highest level; however, this was essentially a continuation of an existing trend (Figure 3). The total during the seven-month project period was 8,161 , which was $11 \%$ more than during the seven preceding months, and $20 \%$ more than during the same period one year earlier. Again, the standard deviation of the seven-month total one year earlier was $9 \%$. Though an increase of $20 \%$ is not likely due to chance variations in enforcement, it still appears to be a continuation of an existing trend. In Topeka, the number of seatbelt citations fluctuated before the project start, dropped deeply thereafter, followed by a slight recovery.

\section{PI\&E Activity}

Narrative descriptions of PI\&E activities in Wichita during the various campaigns are provided in the preceding chapter. Measurable activities were:

- Kickoff events for the various campaigns;

- Participation in TV / radio shows;

- Special events; and

- TV public service announcements.

Each campaign had a kickoff event. In the period being considered, these occurred in September and November of 1991, and in February, April, and June of 1992. Also, special events were held to publicize the program, usually in conjunction with some other topic of general interest. An average of about two special events per month occurred during the project.

Television public service announcements were run by several stations, including the three major stations, $\mathrm{KAKE}, \mathrm{KSNW}$, and $\mathrm{KWCH}$. Estimates are that more than 100 spots were run over the project period. 
Figure 1: DWI Arrests in Wichita and Topeka, January, 1988 - August, 1992

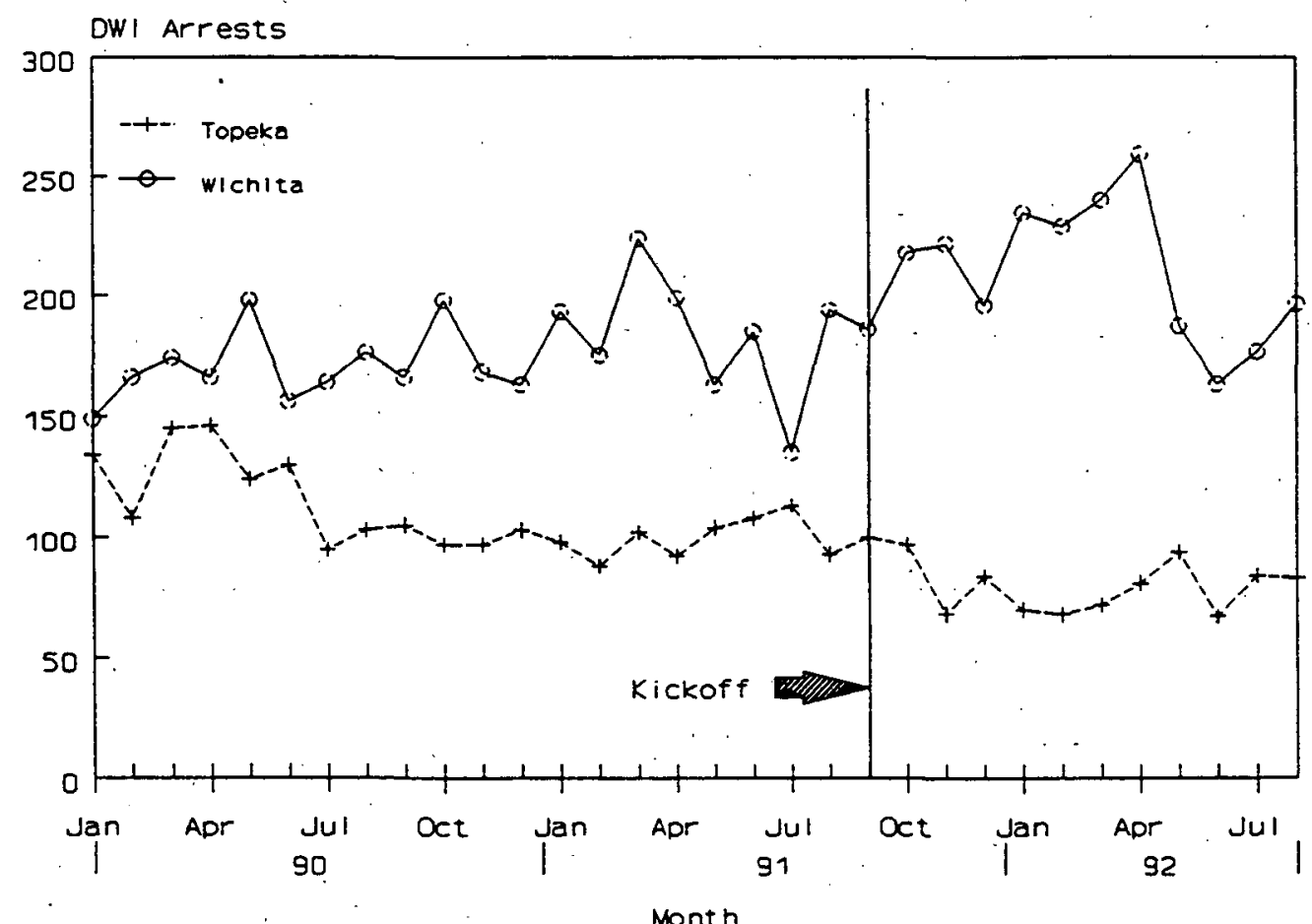

Figure 2: Speeding Citations in Wichita and Topeka, January, 1988 - August, 1992

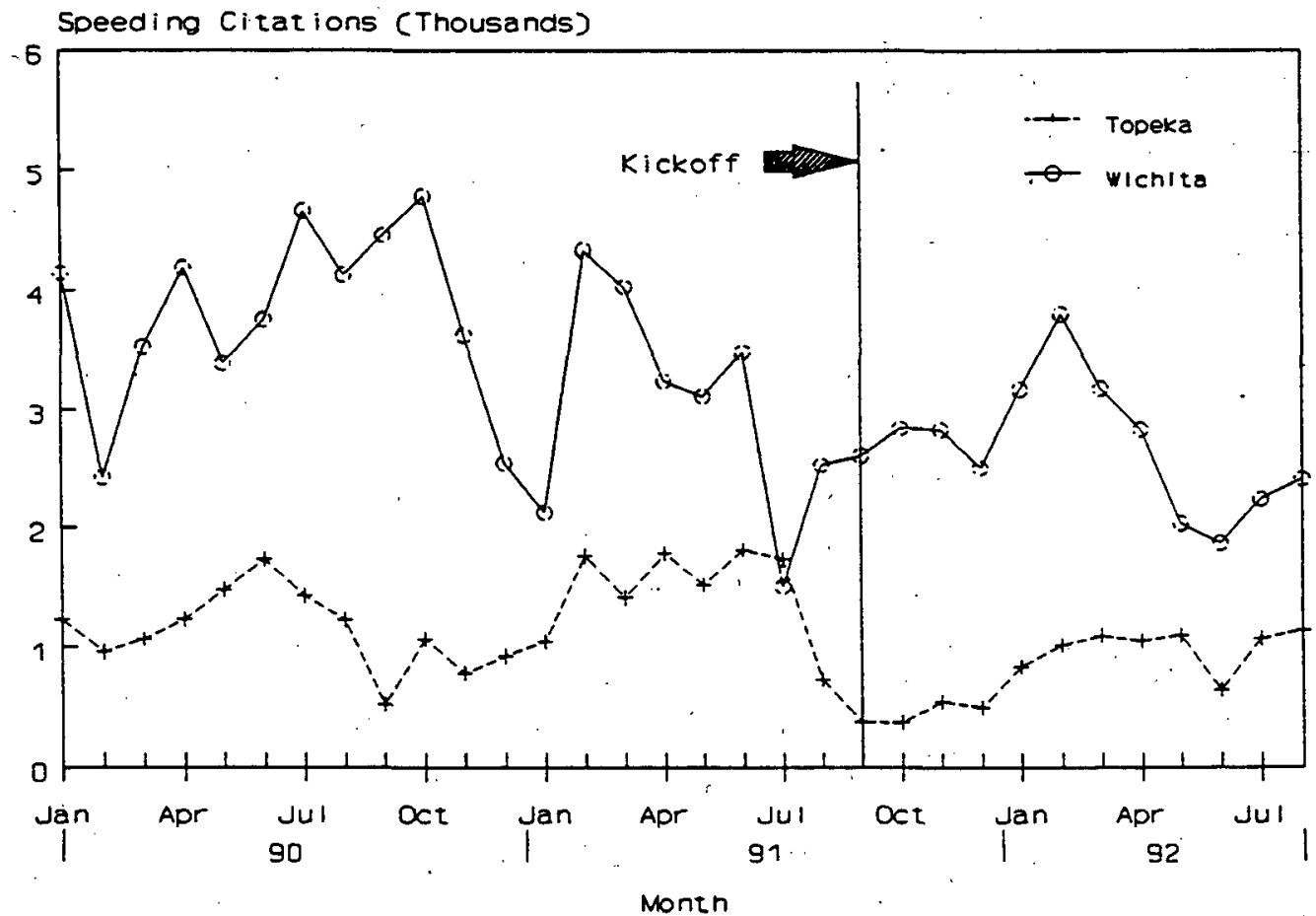


Figure 3: Seatbelt Citations in Wichita and Topeka, January, 1988 - August, 1992

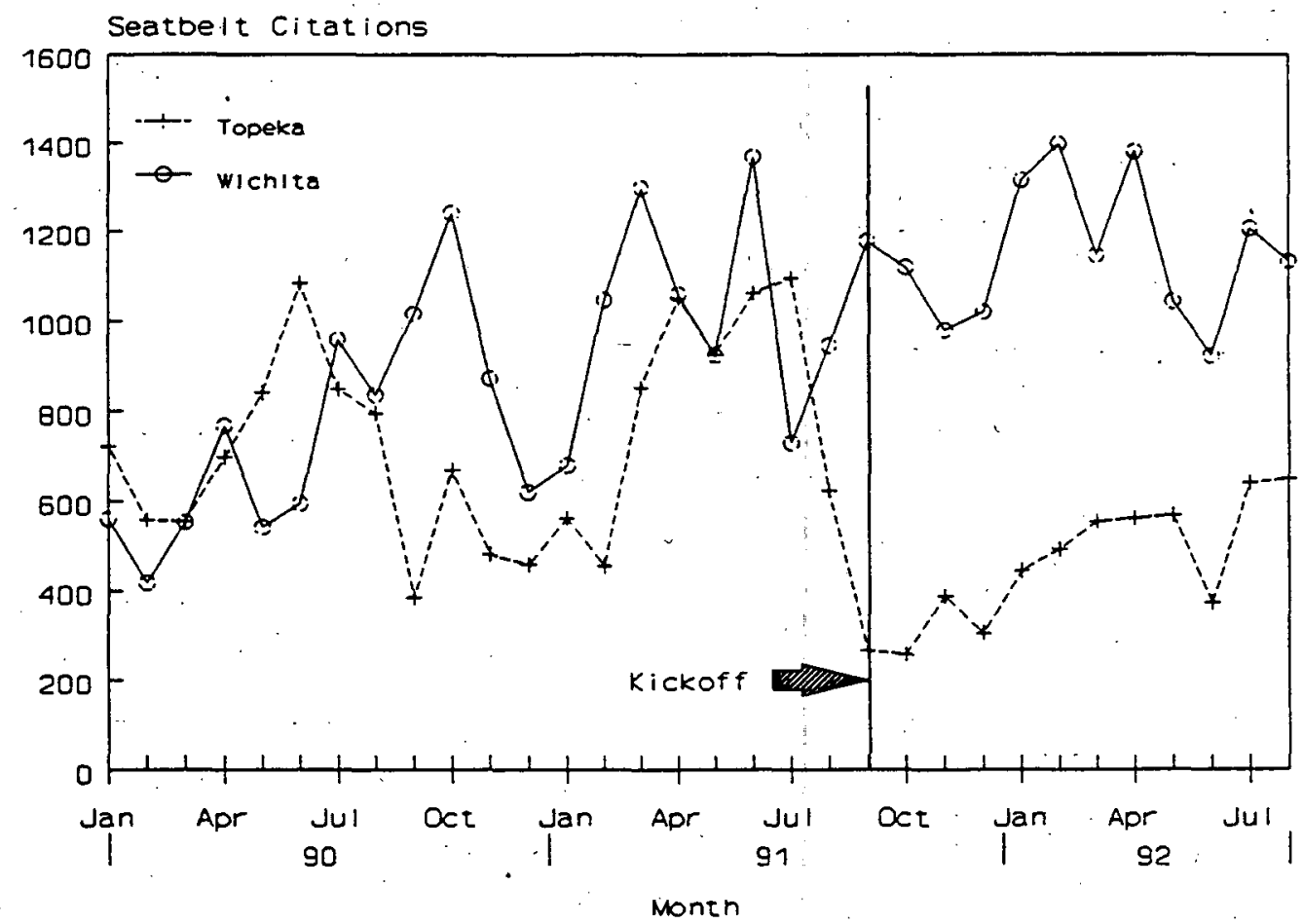

Awareness, Perceived Risk of Enforcement, and Self-Reported Behavior

A total of 3,734 persons responded to the survey, 1,723 in the first wave and 2,011 in the second wave. However, 640 of these responses had to be dropped because the respondents had not been driving during the prior 90 days, the period over which most of the questions applied. This left a total sample size of 3,094 distributed over waves and sites as shown in Table 3. In both sites, $49 \%$ of these were male.

Table 3: Sample Sizes of "Before" and "After" Surveys in Driver License Stations in Wichita and Topeka

\begin{tabular}{||c|c|c|c|c|c|c|}
\hline \multirow{2}{*}{ Site } & \multicolumn{2}{|c|}{ Before } & \multicolumn{2}{c|}{ After } & \multicolumn{2}{c|}{ Total } \\
\cline { 2 - 7 } & $N$ & $x$ & $N$ & $x$ & $N$ & $x$ \\
\hline Wichita & 635 & 45.6 & 912 & 53.6 & 1547 & 50.0 \\
\hline Topeks & 758 & 54.4 & 789 & 46.4 & 1547 & 50.0 \\
\hline Total & 1393 & 100.0 & 1701 & 100.0 & 3094 & 100.0 \\
\hline
\end{tabular}

The age distributions of the 3,094 respondents were very closely matched at the two sites for all age groups except for the under 18 age group ( $2.3 \%$ in Wichita versus 
$4.9 \%$ in Topeka) and the 30 to 49 group ( $48.3 \%$ in Wichita versus $44.5 \%$ in Topeka). These differences in age, though small, were statistically significant at the 0.002 level.

The formal analysis of the survey results used the SAS GLM procedure ${ }^{1}$ using site, survey wave, reason for being in the driver license station (question 1), sex (question 2), age (question 3), and drinking frequency (question 6) as independent variables, and various measures of awareness, perceived enforcement threat, and selfreported behavior as dependent variables in the linear model. For example, the analysis of awareness of DWI messages employed a model of the form:

$$
\text { DWIMESS }=c_{0}+c_{2} s+c_{w} w+c_{1} q_{1}+c_{2} q_{2}+c_{3} q_{3}+c_{6} q_{6}+\epsilon(t)
$$

where DWMMESS was the response to question 4 indicating awareness $(=1)$ or nonawareness $(=0)$ of a DWI message, $s$ was the site (Wichita or Topeka), $w$ the wave ("before" or "after"), and the variables $q_{1}$ to $q_{6}$ the responses to questions 1,2 , 3 , and 6 , respectively. The model permitted us to examine the effect of site and wave on the various dependent variables, adjusted for "reason," sex, age, and drinking frequency. Dependent variables having possible multiple responses (such as "increased," "decreased," or "stayed about the same") rather than dichotomous responses were scored as 1 for a positive response (such as a decrease in speeding), 0 for a no-change or neutral response (such as no change in speeding), and -1 for a negative response (such as an increase in speeding).

The results are summarized in Table 4 which shows the significance (if any) of any changes between the "before" wave and the "after" wave. The results are discussed below for each of the three target violations.

Drinking-Driving. Only non-abstainers were considered in this analysis. There were no statistically significant changes between the "before" and "after" waves for either site for any of the dependent variables. However, there was a positive change in perceived enforcement in Wichita that was significant at the 0.18 level. Examination of the raw data revealed that the positive change in Wichita found by the model was of the order of 4 percentage points: about $44 \%$ of the Wichita respondents to the "before" survey thought that DWI enforcement had increased over the past three months, compared to $48 \%$ for the "after" survey.

Speeding. There were no significant changes in awareness, perceived increase in enforcement, or perceived change in enforcement risk between the two waves in either site. With respect to self-reported behavior, there was also no significant change in Wichita, but there was a significant positive change in Topeka. Again, the raw data were examined to get a rough idea of the magnitude of this change. The

1 GLM is an abbreviation for Generalized Linear ,Model which combines regression, analysis of variance, and analysis of covariance into a single analysis procedure. 
data showed that for the "before" survey, the net percentage of respondents saying that they were speeding less often than they were three months ago (percent speeding less often minus percent speeding more often) was $10.6 \%$. For the "after" survey, this net percentage was $17 \%$.

Seatbelt Use. Wichita showed no significant change in any of measures studied, but Topeka had positive significant $(p<0.05)$ changes in awareness and self-reported behavior. The raw data indicated that in the "before" survey, $27.6 \%$ of the respondents were aware of seatbelt messages, compared to $32.8 \%$ for the "after" survey. For the "before" survey, the net percentage of respondents saying that they were using their seatbelts more often than they were three months ago (percent using more often minus percent using less often) was $12.5 \%$. For the "after" survey, this net percentage was $16.5 \%$.

\section{Measured Speed}

For each session ${ }^{2}$, the following speed characteristics were calculated from the individual measurements, separate for the two lanes, if there was more than one lane:

- Average speed

- Average speed of vehicles exceeding the speed limit (average "excess" speed)

- Percentage of vehicles exceeding the speed limit

- Percentage of vehicles exceeding the speed limit by at least $5 \mathrm{mph}$

- Percentage of vehicles exceeding the speed limit by at least $10 \mathrm{mph}$

In addition, for each of these measures, its "standard error" was calculated. Note that this is not really an error in the usual sense of the word, but that it is a consequence of the random variation of the actual speeds.

Average speed is usually of little interest in the context of speed enforcement, if the majority of drivers drive below or near the speed limit. Their travel habits should not be changed by enforcement; thus the effect of reducing the speed of relatively few speeders should have little effect on the average speed. The average excess speed, however, should show a greater effect; still, it is heavily influenced by the many vehicles which travel slightly above the speed limit, against which usually no enforcement action is taken. However, a few vehicles with very high speeds can influence this average; if their speeds are dramatically reduced, it could have a noticeable effect on the average excess speed.

. The percentage of drivers exceeding the speed limit contains a large number which exceed the limit only by a small amount. In this case, it makes no difference even if the highest speeds are dramatically reduced. Therefore, this measure should not be a very sensitive measure of enforcement effects.

2 A measurement session is defined as the time period during which a set of measurements were taken at a given location during a given shift. 
Table 4: Summary of Analysis of Driver Survey

\begin{tabular}{|c|c|c|}
\hline \multirow{2}{*}{ Measure } & \multicolumn{2}{|c|}{ site } \\
\hline & Wichite & Topeka \\
\hline DWI & & \\
\hline Awareness & ns & ns \\
\hline Enforcement & $\cdots+(t)$ & ns \\
\hline Enforcement Risk & ns & ns \\
\hline Behavior & ns & ns \\
\hline \multicolumn{3}{|l|}{ Speeding } \\
\hline Awareness & ns & ns \\
\hline Enforcement & ns & ns \\
\hline Enforcement Risk & ns & ns \\
\hline Behavior & $\mathrm{ns}$ & $+(* * \pi)$ \\
\hline \multicolumn{3}{|l|}{ Seatbel ts } \\
\hline Awareness & ns & $+(*)$ \\
\hline Enforcement & ns & ns \\
\hline Enforcement Risk & ns & ns \\
\hline Behavior & ns & $+(*)$ \\
\hline
\end{tabular}

Notes:

1. Results for DWI considered non-abstainers only.

2. + denotes a significant positive change

- denotes a significant negative change

ns denotes no significant change

3. (t) $p<.20$

(*) $p<.05$

(ii) $p<.01$

(***) $p<.001$ 
The most meaningful measure of speeding for this project is the percentage of drivers exceeding the speed limit by at least $10 \mathrm{mph}$. Since enforcement actions are often taken only when the limit is exceeded by at least $10 \mathrm{mph}$, this percentage should be the most sensitive measure of the effectiveness of enforcement. The percentage of drivers exceeding the speed limit by at least $5 \mathrm{mph}$ is also a useful measure if enforcement actions carry over to such violations.

Speed measurements in Wichita showed no indication that any of these measures of speeding or travel speeds had declined. There was even a strong suggestion that speeding increased slightly during the program. Topeka also showed no change in speeding, and thus there was no indication that Wichita might have had a relative reduction in speeding. Figure 4 illustrates these findings for percentage of drivers exceeding the speed limit by least $10 \mathrm{mph}$. None of the changes from baseline shown was statistically significant.

\section{Observed Restraint Usage}

The analysis of seatbelt use was similar to the analysis of speeds. Since there were 24 locations in each city, and all observations were made during three hours in the afternoon, no shift factor was included.

There was no suggestion that seatbelt use increased in Wichita (Figure 5). During the third wave, seatbelt use was even down slightly. Topeka also showed no change in seatbelt use, so there was also no relative increase in seatbelt use in Wichita.

\section{Accidents}

As indicated above, our measurements of vehicle speeds showed no decline in speeding, and our observations of seatbelt use gave no indication that seatbelt use increased. Therefore, a reduction in injury accidents could not be expected, and our accident analyses concentrated on those accident types that were more likely to involve alcohol. The few analyses of injury accidents that were performed confirmed this expectation and provided no indication of any program effect on accidents related to speeding or non-use of seatbelts. ${ }^{3}$

Several different time series of types of accidents indicating possible alcohol involvement were examined. These were:

Number of police-reported alcohol-related accidents

Number of nighttime accidents

Number of nighttime injury accidents

Number of nighttime single-vehicle accidents

Number of nighttime single-vehicle injury accidents

3 The details of the analyses leading to these and other findings about possible effects of the Trifecta program on accidents are discussed in Appendix $C$. 
Figure 4: Change in Percentage of Drivers Exceeding the Speed Limit by at Least 10 mph in Wichita and Topeka, April, 1991 - July, 1992

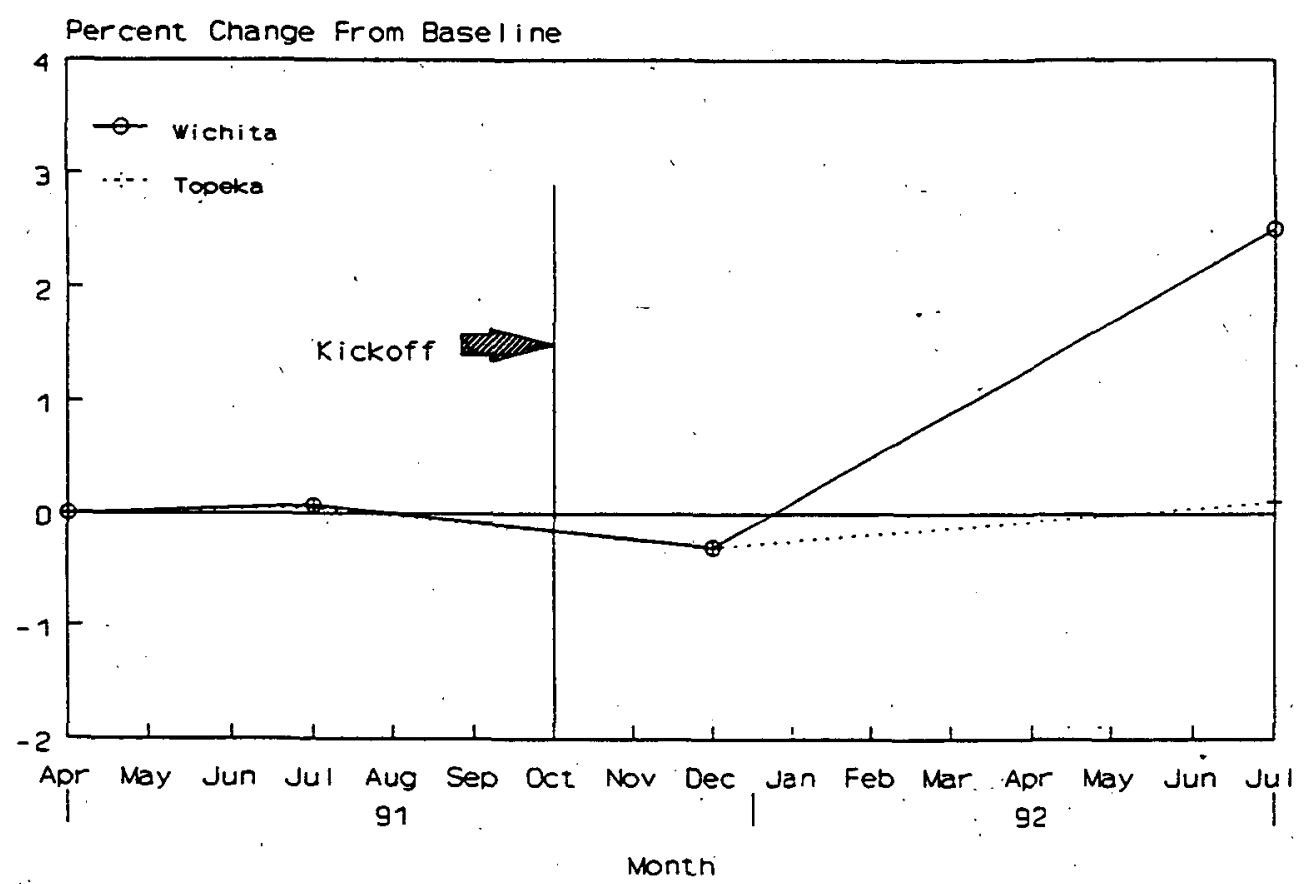

Figure 5: Change in Percentage of Seatbelt Users, April, 1991 - July, 1992

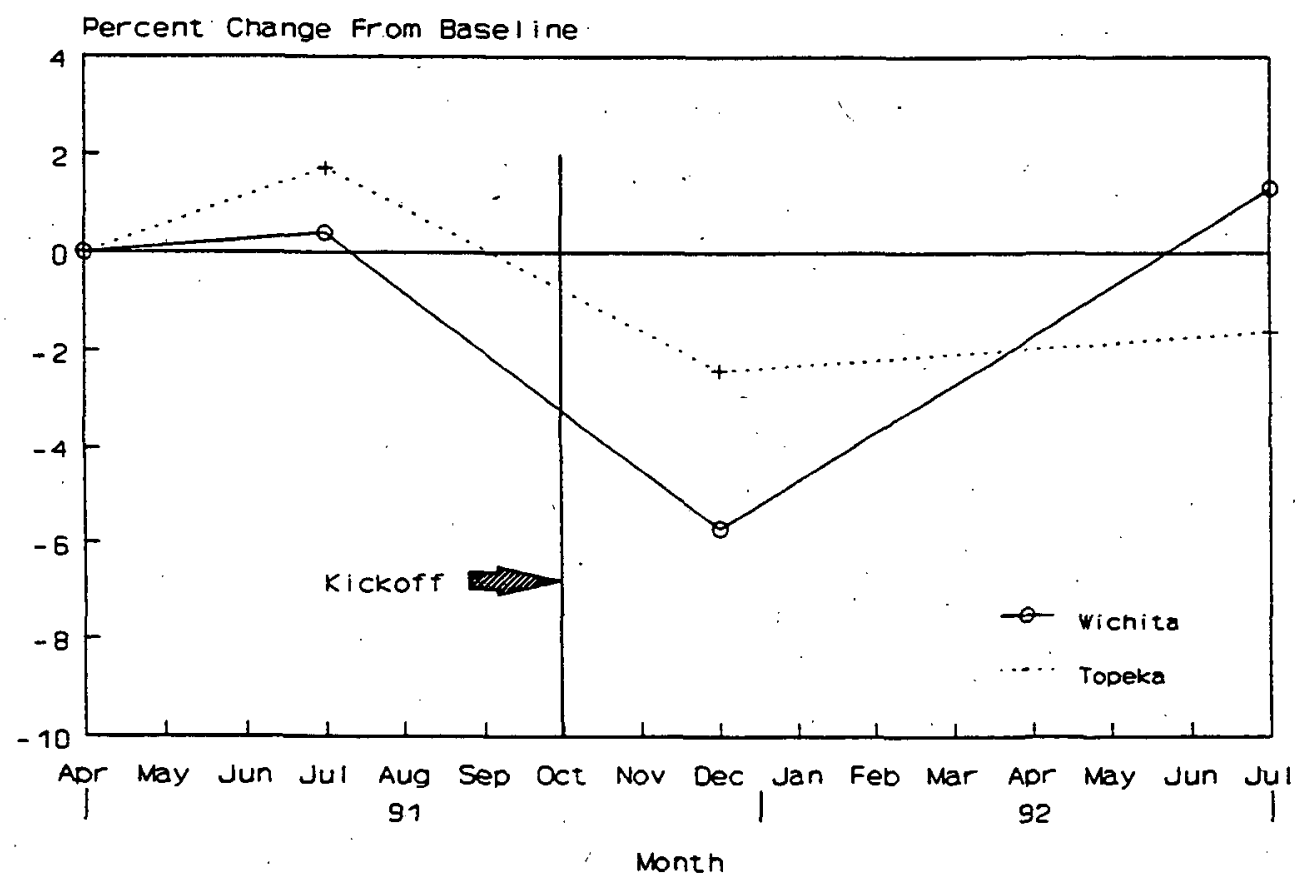


The first of these accident types, police-reported alcohol-related accidents, is believed to be the least reliable indicator of alcohol involvement, since it is based on the opinion of the investigating officer which might have been influenced by external, non-random factors. Such factors include training that might have occurred during the program period or other occurrences that increased or decreased awareness of the alcohol-crash problem. The last four of these accident types are commonly used "proxy" measures of alcohol-related crashes, and were given the most attention in our analyses.

A variety of analytic methods were used in the analyses of alcohol-related accidents, ranging from visual examination of the data to several kinds of models, including regression models, general linear models, and, finally, ARIMA models. Terms accounting for trends and seasonal effects were included in many of the models as were terms that acted as "control" variables to account for non-program effects that might have have occurred during the time period studied.

The results of the analyses Table 5: Summary of Results of ARIMA Anausing the ARIMA models of prox- Iyses of Proxies of Alcohol-Related Accidents in ies of alcohol-related crashes are Wichita

summarized in Table 5. They indicate reductions in alcohol-related crashes ranging from $20 \%$ to $35 \%$. All of these reductions are highly significant, with the probability that they could be due to chance alone being less than 0.005 . Plots of the last two of these series are shown in Figure 6 and Figure 7. The graphs show the raw data taken from the Kansas Department of

\begin{tabular}{|l|l|}
\hline \multicolumn{1}{|c|}{ Type of Accident } & \multicolumn{1}{|c|}{$\begin{array}{c}\text { Reduction in Acci- } \\
\text { dents as } \text { Mean of the }\end{array}$} \\
\hline Nighttime & $20 \%(30 / 148)$ \\
\hline $\begin{array}{l}\text { Nighttime Injury } \\
\begin{array}{l}\text { Nighttime Single-Ve- } \\
\text { hicle }\end{array}\end{array}$ & $21 \%(14 / 65)$ \\
\hline $\begin{array}{l}\text { Nighttime Single-Ve- } \\
\text { hicle Injury }\end{array}$ & $23 \%(24 / 69)$ \\
\hline
\end{tabular}

Transportation database, plus ARIMA forecasts based on these data. The intervention is depicted as a solid vertical line. Forecasts of accidents without the intervention coinciding with the Traffic Trifecta program are indicated by the dotted lines, while forecasts of accidents with the intervention coinciding with the Traffic Trifecta program are indicated by the solid lines. 
Figure 6: Nighttime Single Vehicle Accidents in Wichita, Topeka as a Control

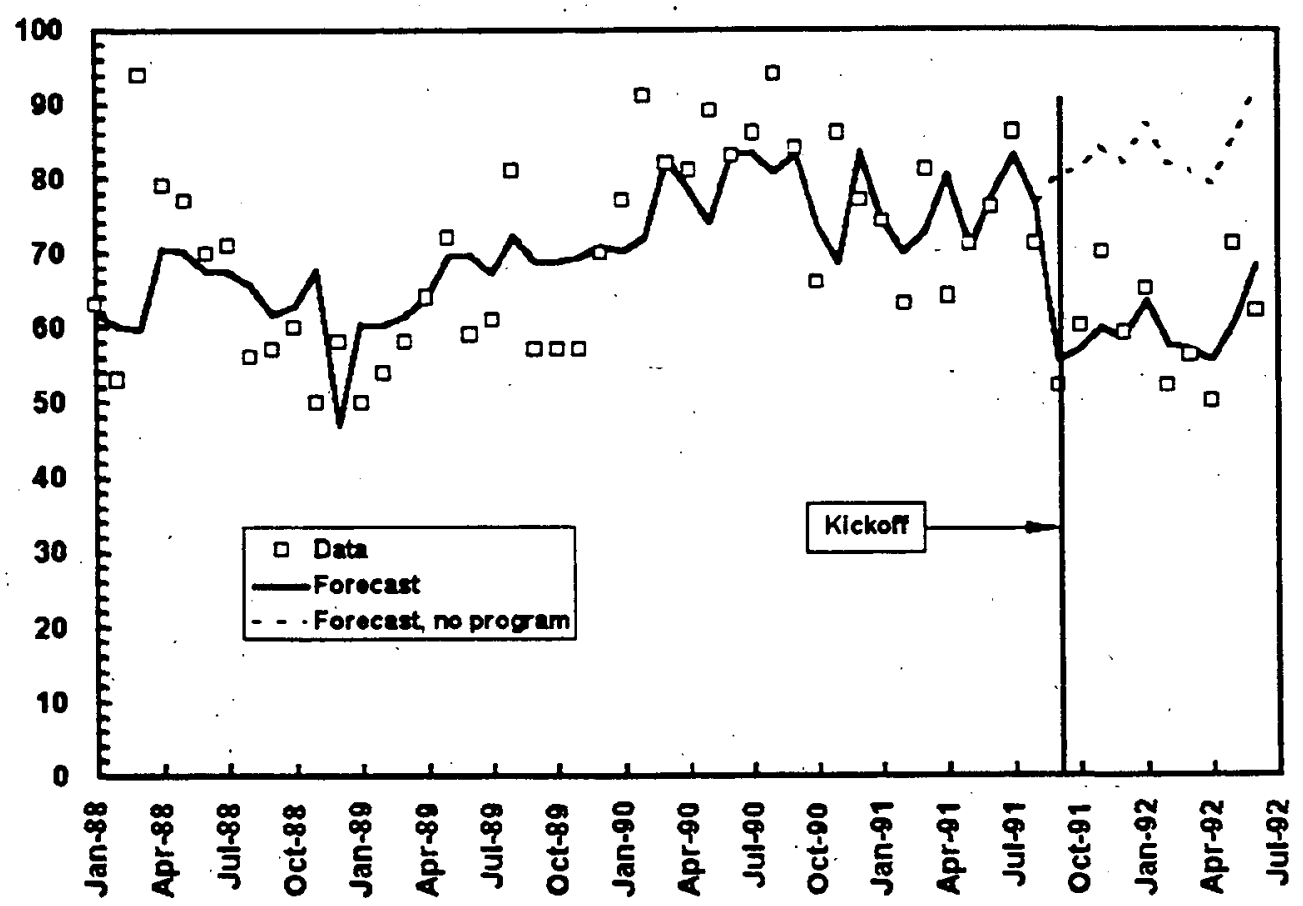

Figure 7: Nighttime Single Vehicle Injury Accidents in Wichita, Topeka as a Control

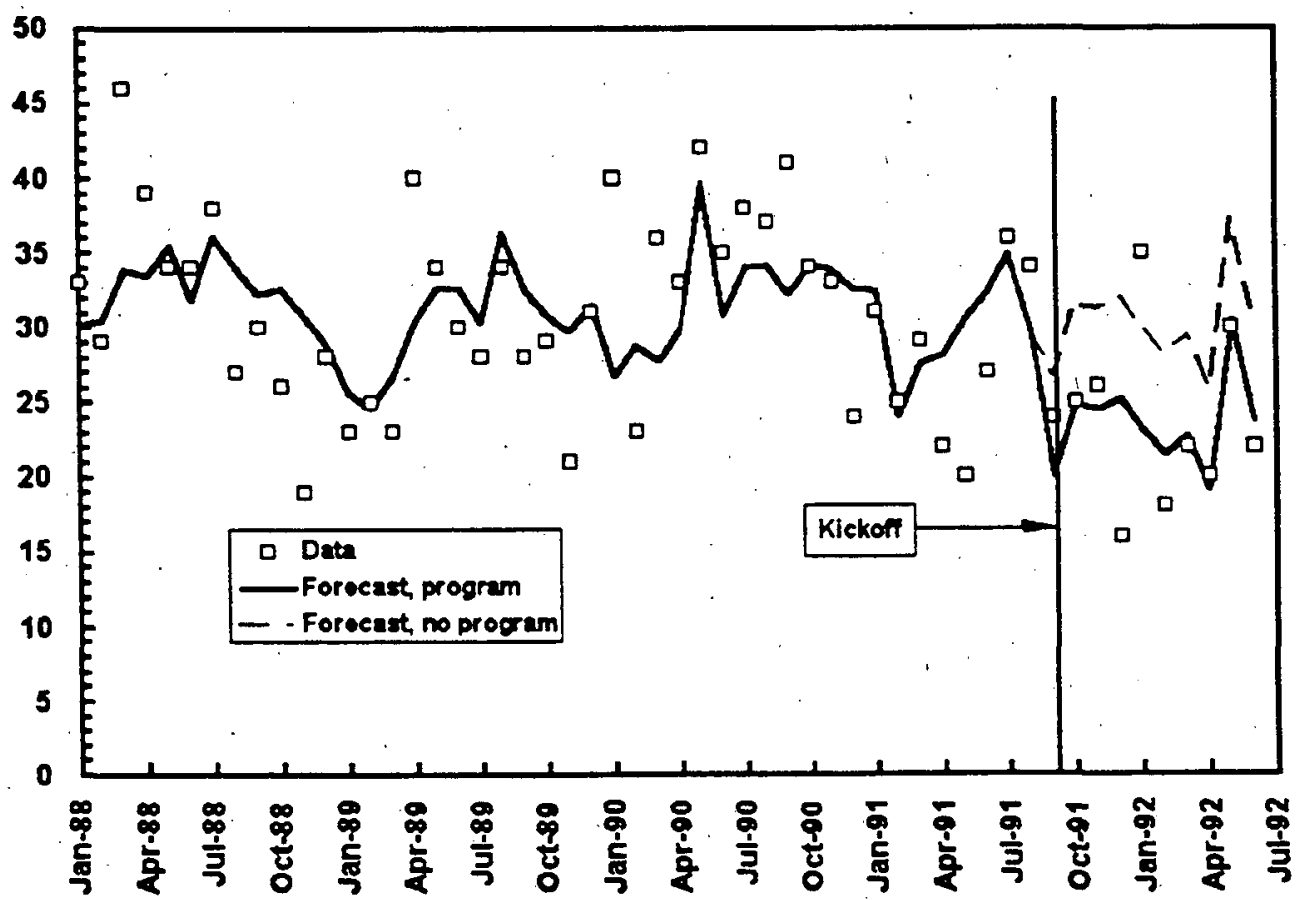




\section{SYNTHESIS AND INTERPRETATION OF RESULLTS}

By comparing 10 months of data from Wichita with data for the same period in Topeka, the effect of the Wichita combined-enforcement program relative to the Topeka nominal-enforcement effort was estimated. Table 6 summarizes various measures of activity and outcome relative to the target law violations of the Wichita project. With respect to $D W I$, there was a significant increase in enforcement in Wichita during most of the project period. This increase was accompanied by increased PI\&E activity throughout the project period. However, there was no change in awareness of project messages related to DWI or the combined enforcement program, nor was there any change in self-reported frequency of drinkingdriving. On the other hand, there was some evidence that perceived risk of DWI enforcement increased in Wichita, and several proxies of accidents involving alcohol were compatible with a program effect on DWI. These proxies declined some $20 \%$ to $35 \%$ during the Wichita project.

With respect to speeding, enforcement activity in Wichita actually decreased even though there was an increase in PI\&E activity. Thus, we would not expect any positive changes in outcome, and in fact, none were found. Likewise, there were also no positive changes in Wichita with respect to outcome of the seatbelt component of the combined enforcement program, even though there were positive increases in both enforcement and PI\&E activity throughout most of the project period.

Thus, in Wichita, circumstances beyond the control of the project prevented a fair test of the combined enforcement concept. The speeding enforcement effort and, to some extent, the seatbelt enforcement effort, were neutralized by the transfer of resources and command emphasis to other, non-traffic enforcement activities. The program's effect on DWI could plausibly be attributed to the maintenance of a significant DWI enforcement threat strongly supported by PI\&E during the project period. Conceivably, increased enforcement of speeding and seatbelt violations might also have shown a positive effect had the Wichita Police Department been able to maintain the level of enforcement activity initially planned. However, in the face of extreme pressures on limited police resources, the Department apparently made a conscious decision to concentrate on DWI rather than on speeding or seatbelt violations. 
Table 6: Summary of Project Activity and Outcome

\begin{tabular}{|c|c|c|c|}
\hline \multirow{2}{*}{$\begin{array}{l}\text { Target } \\
\text { Behavior }\end{array}$} & \multirow{2}{*}{ Item } & \multicolumn{2}{|c|}{ site } \\
\hline & & Wichita & Topeka \\
\hline DUI & $\begin{array}{l}\text { Activity } \\
\text { Enforcement Level } \\
\text { PI\&E } \\
\text { Outcome } \\
\text { Awareness } \\
\text { Perceived Enforcement Risk } \\
\text { Self-Reported DUI } \\
\text { Accidents }\end{array}$ & $\begin{array}{l}\text { Increase } \\
\text { Increase } \\
\text { No change } \\
\text { Possible increase } \\
\text { No change } \\
\text { Decrease }\end{array}$ & $\begin{array}{l}\text { No change } \\
\text { Ho change } \\
\text { No change } \\
\text { No change } \\
\text { No change } \\
\text { No change }\end{array}$ \\
\hline Speeding & $\begin{array}{l}\text { Activity } \\
\text { Enforcement Level } \\
\text { Pl\&E } \\
\text { Outcome } \\
\text { Awareness } \\
\text { Perceived Enforcement Risk } \\
\text { Self-Reported Speeding } \\
\text { Measured Speeding } \\
\text { Accidents }\end{array}$ & $\begin{array}{l}\text { Decrease } \\
\text { Increase } \\
\text { No change } \\
\text { No change } \\
\text { No change } \\
\text { No change } \\
\text { No change }\end{array}$ & $\begin{array}{l}\text { Decrease } \\
\text { Ho change } \\
\text { No change } \\
\text { No change } \\
\text { Decrease } \\
\text { No change } \\
\text { No change }\end{array}$ \\
\hline $\begin{array}{l}\text { Seatbelt } \\
\text { Use }\end{array}$ & $\begin{array}{l}\text { Activity } \\
\text { Enforcement Level } \\
\text { PI\&E } \\
\text { Qutcome } \\
\text { Awareness } \\
\text { Perceived Enforcement Risk } \\
\text { Self-Reported Use } \\
\text { Measured Use } \\
\text { Accidents }\end{array}$ & $\begin{array}{l}\text { Increase } \\
\text { Increase } \\
\text { Ho change } \\
\text { Ho change } \\
\text { Ho change } \\
\text { No change } \\
\text { No change }\end{array}$ & $\begin{array}{l}\text { Decrease } \\
\text { No change } \\
\text { slight increase } \\
\text { No change } \\
\text { slight increase } \\
\text { No change } \\
\text { No change }\end{array}$ \\
\hline
\end{tabular}




\section{5 - CONCLUSIONS}

The major conclusions of the Wichita field test are:

With respect to DWI

- Wichita's combined-enforcement program was more effective against alcoholrelated crashes than was its prior enforcement program.

- Wichita's combined-enforcement program was more effective against alcoholrelated crashes than was Topeka's nominal enforcement program.

With respect to speeding and seatbelt use

- Wichita's combined-enforcement program was neither less effective nor more effective than was its prior enforcement program.

- Wichita's combined-enforcement program was neither less effective nor more effective than was Topeka's nominal enforcement program;

The Wichita project was based on a design concept requiring:

- use of high-intensity, combined-enforcement strategies incorporating both new and traditional techniques; and

- heavy use of public information and education tailored to match each of the combined-enforcement strategies.

As implemented, Wichita's combined-enforcement effort against DWI involved a significant increase in enforcement intensity (as measured by number of citations and number of officers assigned to enforce the target violation), but the enforcement intensity against the other two target violations either decreased or increased only moderately. Also, while the project did include a comprehensive PI\&E campaign, the phasing of that campaign did not always coincide with the phasing of the various combined enforcement strategies. Therefore, the basic requirements of the combinedenforcement concept were only partially met in Wichita. The effort against the one target violation that did meet most of the requirements of the project (DWI) resulted in reductions in proxies of alcohol-related crashes of at least $20 \%$.

Thus, the results of the program suggest that an enforcement / PI\&E campaign that stresses more than one target violation can be effective against at least one of those violations. Whether it can also be effective against more than one violation remains to be determined, but research indicates that a crucial condition for multiviolation effectiveness is significantly increased enforcement of all of the target violations. Because of extraordinary demands on police resources that arose during the project, that condition was clearly not met in Wichita despite a good PI\&E effort. 


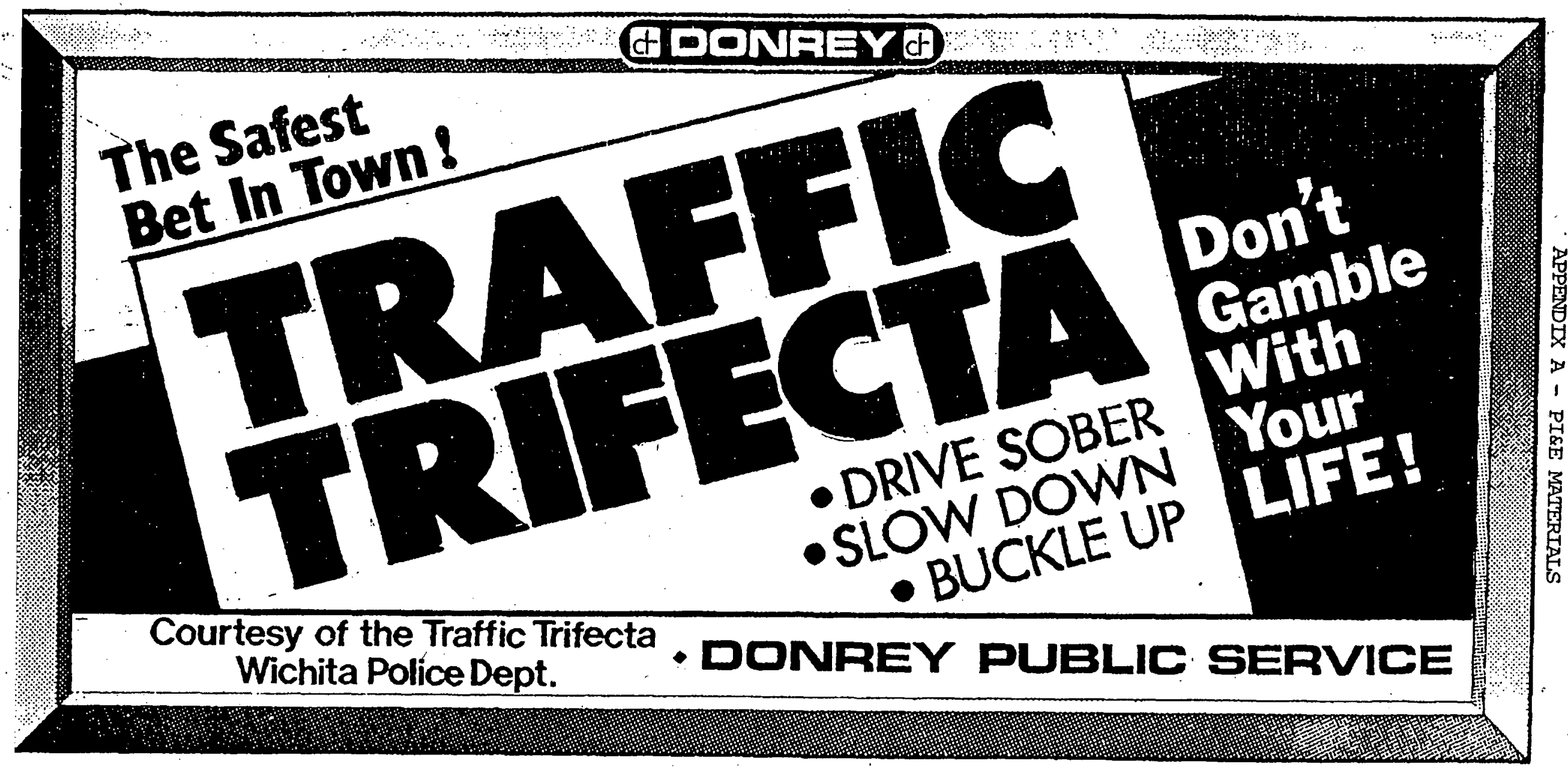

SIZE: 36 SHEET QUANTITY: POSTING DATE: NOTE:

$\frac{\cdots \cdots}{\cdots \cdots \cdots}, \cdots$
DONREY OUTDOOR ADVERTISING CO. WICHITA, KANSAS ARTWORK APPROVAL 


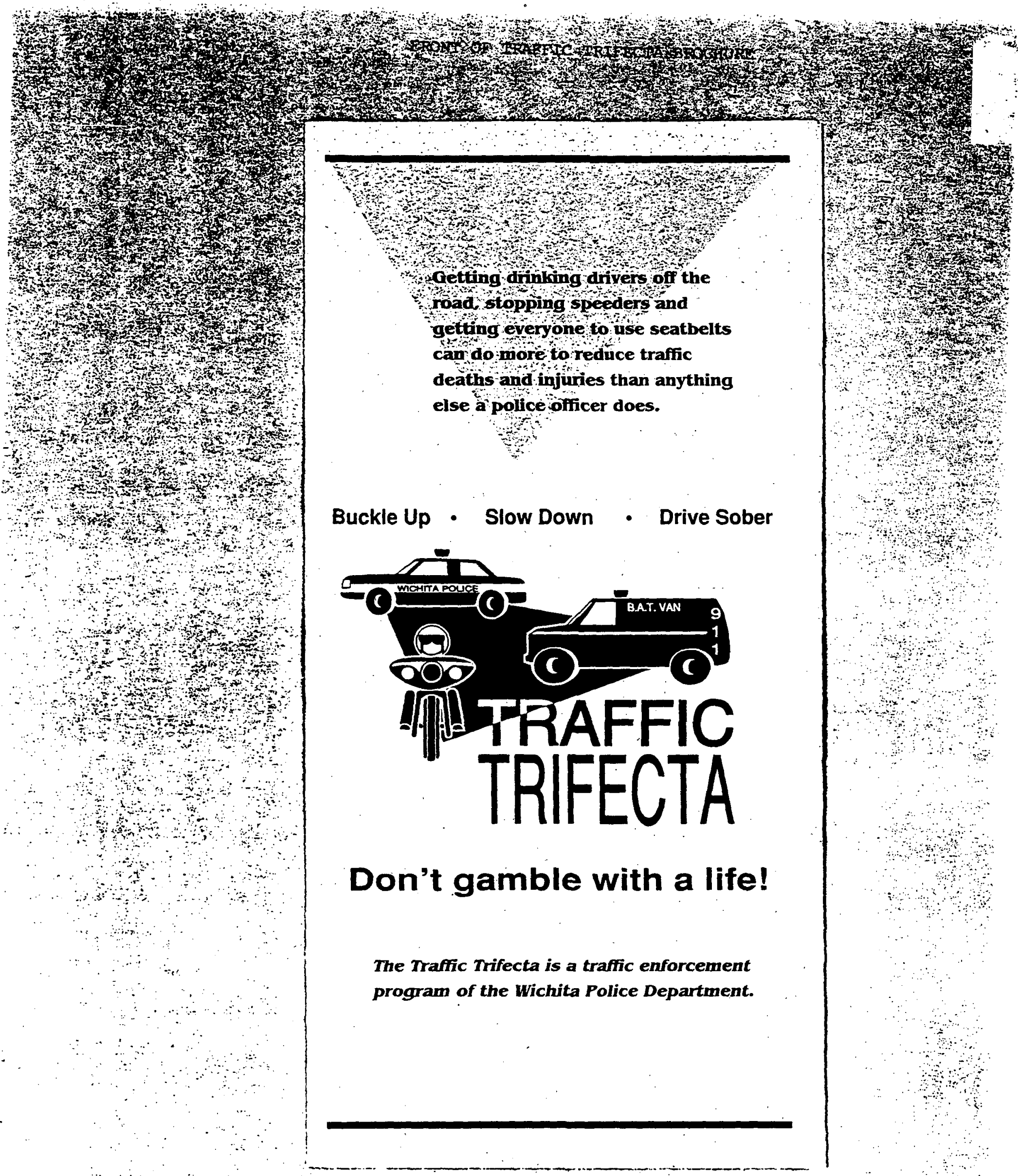




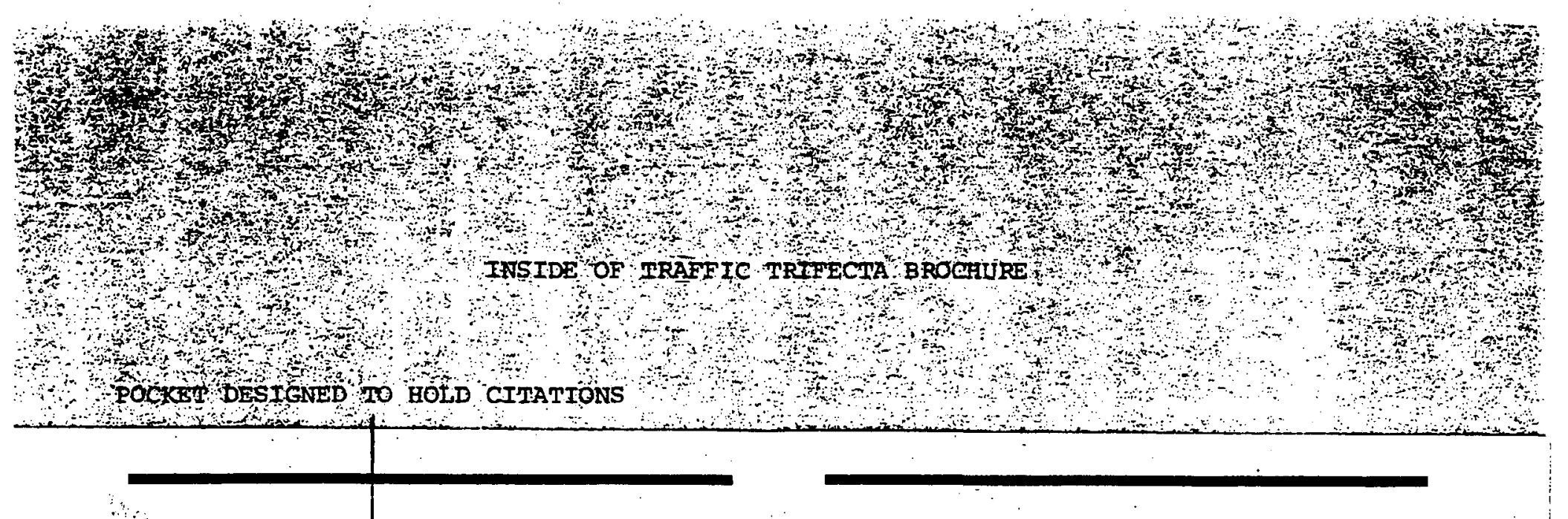

\section{Sobriety Checkpoints}

Sobriety check points will be utilized at announced times and locations throughout the city. Those drivers who are sober will be passed through quickly. Drivers showing signs of impairment such as the odor of alcohol or other physical traits are carefully investigated.

\section{D.U.I. Equipment}

Hand held breath testing devices allow officers to quickly and accurately determine at roadside which motorists have been drinking. Mobile units with breath testing equipment are available so that the breath test which is admissible as evidence in court can be given on the spot. This technology allows officers to speed up processing the D.U.I. driver and be back on the road quickly.

\section{- Drinking and Driving \\ - Speeding, and \\ - Seat Belt use}

\section{- Combined Enforcement}

Officers are using these enforcement strategies to get motorists to slow down, put a sober driver behind the wheel and get both children and adults to use seat belts.

\section{Power Shift}

The Wichita Police Department is operating a dedicated traffic enforcement unit. These specially trained officers patrol when and where speeding and D.U.I. violations are likely to occur. 


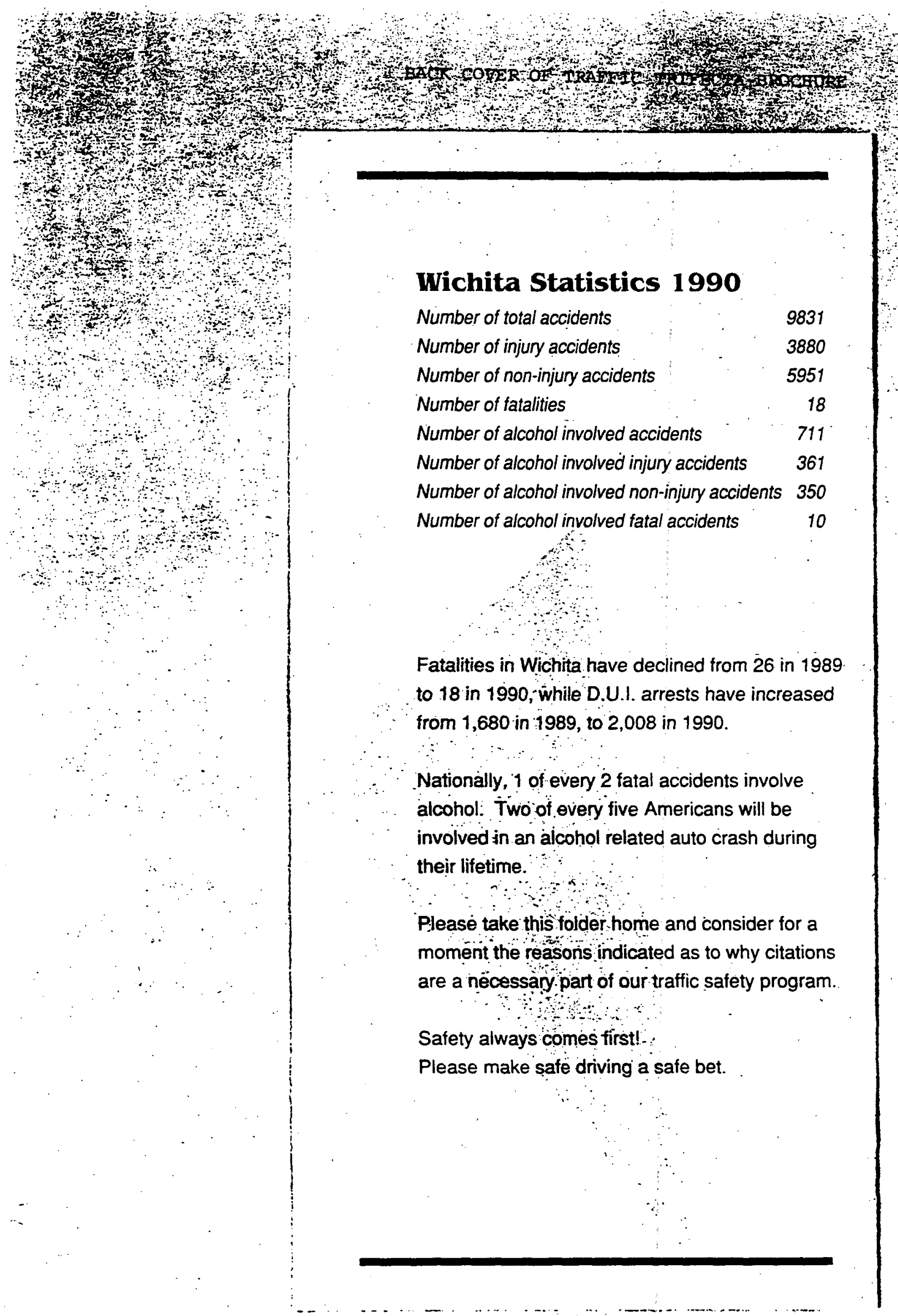




\section{WICHITA POLICE DEPARTMENT}

DePartmental NeWSletter

OCTOBER 1991

V.OLUME 8

\section{CITIZEN POLICE ACADEMY}

The Citizen Police Academy is an eleven-week program designed to provide residents with a working knowledge and background of the Wichita Police Department. The Academy consists of a series of discussion sessions held once a week on Tuesday evenings, from 6:30 to 9:30 P.M. Instruction each. week provides an overview of various areas in law enforcement work.

Officer Kurt McMillian has been selected as the coordinator of the first Academy and reports that he received over 70 applications from interested citizens. The present class consists of 36 citizens from a. varied and diverse background.

The topics of discussion includes police training, communications, policies and procedures, internal affairs, criminal investigation, and patrol functions. The instruction consists of demonstrations, tours, lectures, and a ride-along shitt with police patrol officers.

The intent of the Citizen Police Academy is to provide an "Understanding Through Education." It is being presented to provide residents basic information about the police profession and the work of the Police Department --its policies and procedures. The ultimate goal of this program is to improve the relationship between the community and the police officer.

This program provides citizens the opportunity; to learn about local law enforcement, ask questions, and express any concerns about law enforcement in the City of Wichita. The Academy also provides a means for the residents and police officials to share and exchange information about the police profession.

Graduation for the first class will be on November 19, 1991.

Refreshments will be served and all officers are invited to attend. Tentative plans for the next class call for it to start on January 7, 1992.

Any citizen interested in applying for admission may call 268-4207 for further information.

\section{TRAFFIC TRIFECTA}

Traffic Trifecta is a public safety program of the Wichita Police Department which combines three enforcement areas:

. Drinking and Driving

- Speeding, and

- Seat Belt use

Officers are using these enforcement strategies to get motorists to slow down, put a sober driver behind the wheel and get both children and adults to use seat belts.

Sobriety check points will be utilized at announced times and locations throughout the city. Those drivers who are sober will be passed through quickly. Drivers showing signs of impairment such as the odor of alcohol or other physical traits are carefully investigated.

Hand held breath testing devices allow officers to quickly and accurately determine at roadside which motorists have been drinking. Mobile units with breath testing equipment are available so that the breath test which is admissible as evidence in court can be given on the spot. This technology allows officers to speed up processing the D.U.I. driver and be back on the road quickly.

Motorcycles equipped with hand held radar units will be utilized throughout the city. These officers can easily pick out speeders in traffic. Those drivers stopped for speeding violations will then be checked for alcohol impairment and seat belt use.

Enforcement of Kansas seat belt laws is part of all traffic stops performed by the Wichita Police. Anyone stopped and ticketed for not having children under age 14 buckled in seats belts or child safety seats, will be given another citation if they are not wearing their own seat belts.

Getting drinking drivers off the road, stopping speeders and getting everyone to use seatbelts can do more to reduce traffic deaths and injuries than anything else you as a police officer can do.

Remember, safety always comes first! Please make safe driving a safe bet. 


\section{Appendix B - Driver Survey Questionnaire}

We need your help in providing information about highway safety issues. Your answers will be used for statistical purposes only. Please do not write your name on this form.

1. Why are you at the driver's license office? (CIRCLE ONE)
a. To get first license
c. To have license reinstated
e. other
b. To renew currently valid license
d. To get an I.D. only

2. Your sex? (CIRCLE ONE)
a. Male
๖. Female

3. Your age? (CIRCLE ONE)
a. under 18
c. $21-24$
b. $18-20$
d. $25-29$
e. $30-49$
g. Over 65

4. What messages about enforcement of laws on drunken-driving, speeding, or not using a seatbelt have you heard, seen, or read in the last three months (on TV, radio, in the newspaper, posters, etc.)? Please, write in.

The message

Where seen, heard, or read

5. Have you noticed any increase in enforcement of any of the following traffic laws in the past three months? (CIRCLE ALL THAT APPLY)
a. Drunk driving
b. Speeding
c. Not using a seatbelt

6. How often do you drink beer, wine or liquor? (CIRCLE ONE)
a. Every day
c. Once a week
e. Less than once a month
b. Several times a week
d. Once a month
f. Never

7. Within the last three months, how often do you think you may have driven after drinking too much? (CIRCLE ONE)
a. Every day
b. Several times a week
c. Once a week
e. Less than once a month
d. Once a month
f. Never

8. A. Compared with three months ago, are you driving after drinking: (CIRCLE ONE)
a. More often?
b. Less often?
c. About the same?
d. Do not drive after drinking
B. If it changed, please say why: 
9. A. Compared with three months ago, are you speeding: (CIRCLE ONE)
a. More often?
b. Less often?
c. About the same?
d. Do not speed
B. If your speeding changed, please say why:

10. A. Compared with three months ago, are you using your seatbelt: (CIRCLE ONE)
a. More often?
b. Less often?
c. About the same?
d. Always use seatbelt
B. If your seatbelt usage has changed, please say why:

11. Compared with three months ago, would you say that the chances of a drunken driver getting caught by the police have: (CIRCLE ONE)
a. Increased?
b. Decreased?
c. Stayed about the same?

12. Compared with three months ago, would you say that the chances of a speeder getting caught by the police have: (CIRCLE ONE)
a. Increased?
b. Decreased?
c. Stayed about the same?

13. Compared with three months ago, would you say that the chances of a person not using a seatbelt getting caught by the police have: (CIRCLE ONE)
a. Increased?
b. Decreased?
c. Stayed about the same? 


\section{APPENDIX C - ANALYSIS OF ACCIDENT DATA}

This appendix presents the results of our analysis of the accident data obtained after the termination of the combined enforcement program in Wichita. Since there was no indication that speeding declined, or that seatbelt use increased, a reduction of injury accidents in general could not be expected; therefore, the analysis concentrated on those accident types that were more likely to involve alcohol. However, a few analyses of all injury accidents (which are potential indicators of speeding or seatbelt use) were performed.

\section{PRELIMINARY EXAMINATION OF THE ACCIDENT DATA}

Figure C-1 shows all accidents over time. In Wichita, there appears to be a very slight downtrend, but in Topeka, there is an apparent uptrend which is interrupted near April, 1991. This raised some doubts about the suitability of Topeka as control site for Wichita with respect to accidents, but this question was studied by more thorough analyses.

Figure C-2 shows the number of accidents with reported alcohol involvement. In Wichita, there is an overall downtrend, but the numbers during the program could possibly be slightly higher than during the period immediately before. In Topeka, the numbers are essentially level, except for a drop during the program in Wichita.

Figure C-3 shows nighttime single-vehicle injury accidents, a relatively large proportion of which are likely to involve alcohol. In Wichita, there is a clear longterm downward trend, with large fluctuations. In Topeka, there is a suggestion of an increasing trend until about July 1990, and a slight decline thereafter.

Overall, these graphs made no clear suggestion of an effect of the program on DWI; thus more thorough quantitative analyses were needed.

\section{ACCIDENTS REPORTED TO INVOLVE SPEED}

Figure $\mathrm{C}-4$ shows the number of accidents reported by the police as involving speed in Wichita and Topeka. A strong long-term downtrend is apparent in Wichita, and there appears to be a much weaker declining trend in Topeka. During the earlier months, the number of accidents in Wichita is much higher than in Topeka. However, during the last months, they are often equal in the two cities. Most striking, however, are several extreme "spikes," and some lesser "peaks," which are common to both series. Part of this effect is a strong seasonal pattern which is very similar at both sites, but part of it appears to be distinct events, for example, the spikes in February, 1988; February, 1989; February, 1990; and November, 1991. Without explaining such dramatic changes and quantitatively modeling them, standard analyses of these accident numbers would be meaningless. Unfortunately, none of our contacts in Kansas were able to offer any such explanation.

\section{ACCIDENTS REPORTED TO INVOLVE ALCOHOL}

The most direct measure of alcohol involvement available is police-reported alcohol involvement. It is well known that this is neither a comprehensive, nor a reliable measure; however, because of its directness, we did analyze it. 
Figure C-1: All Accidents in Wichita and Topeka, January, 1988 to June, 1992

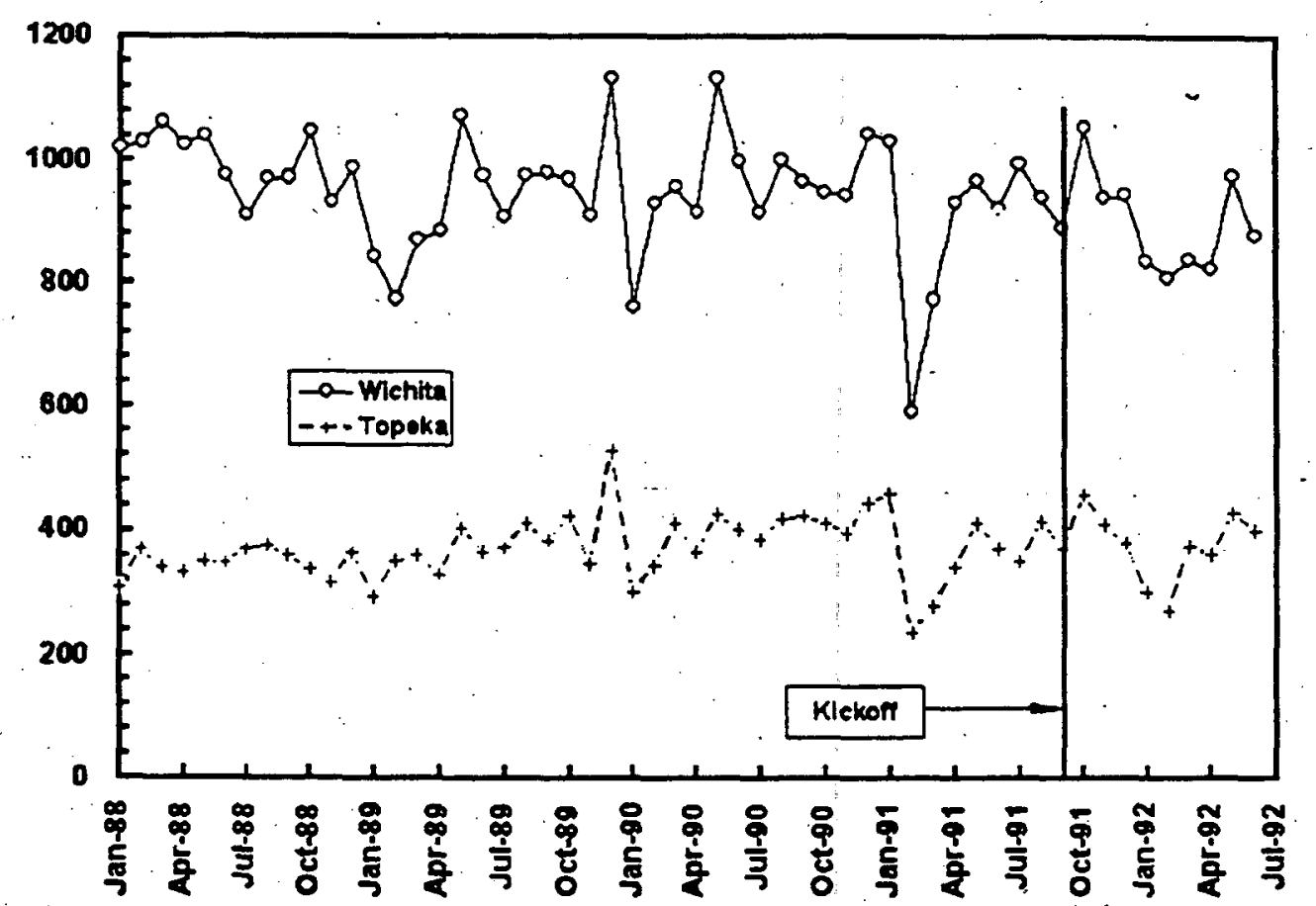

Figure C-2: Police-Reported Alcohol-Involved Accidents in Wichita and Topeka, January, 1988 to June, 1992

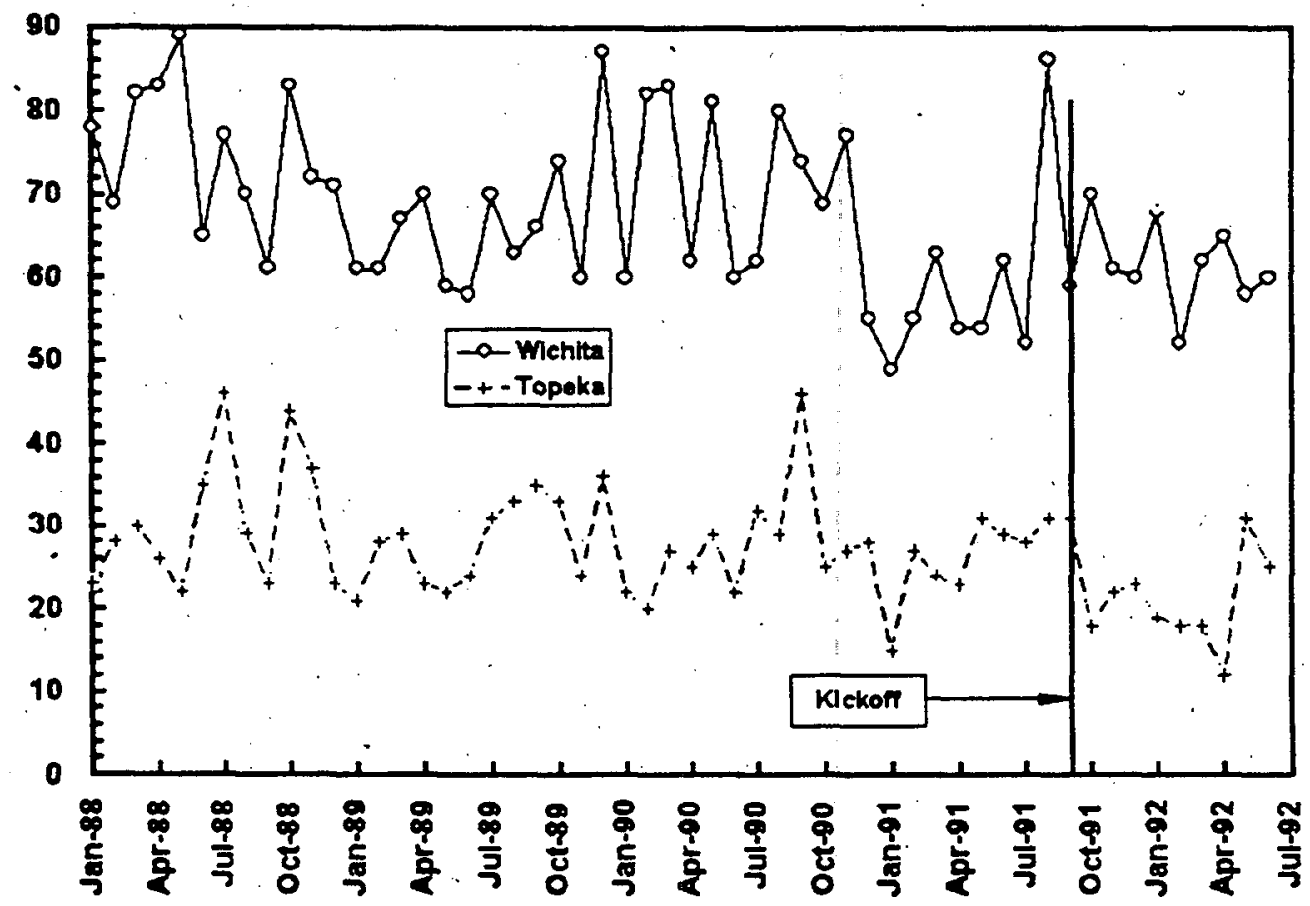


Figure C-3: Nighttime Single-Vehicle Injury Accidents in Wichita and Topeka, January, 1988 to June, 1992

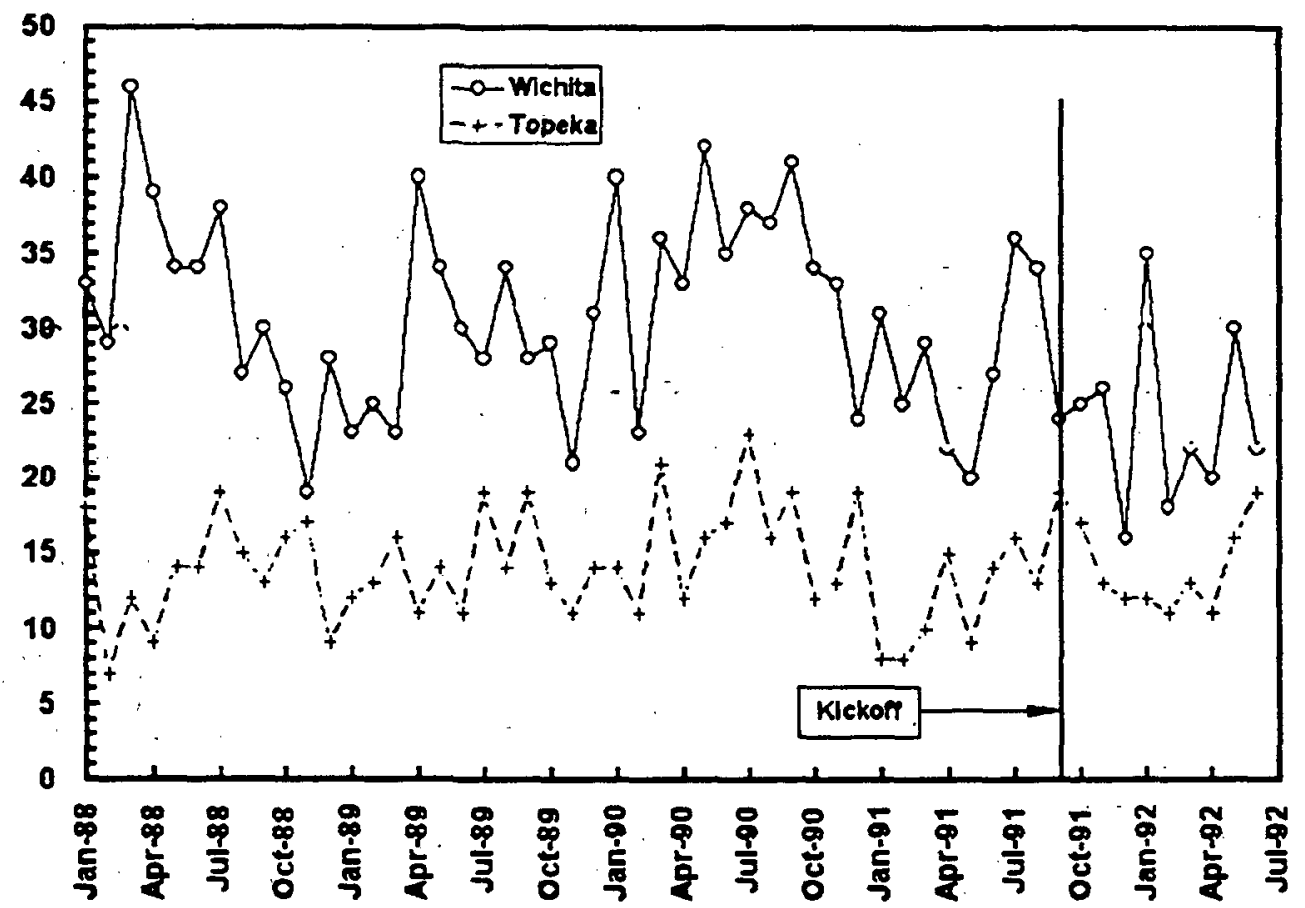

Figure C-4: Police-Reported Speeding-Involved Accidents in Wichita and Topeka, January, 1988 to June, 1992

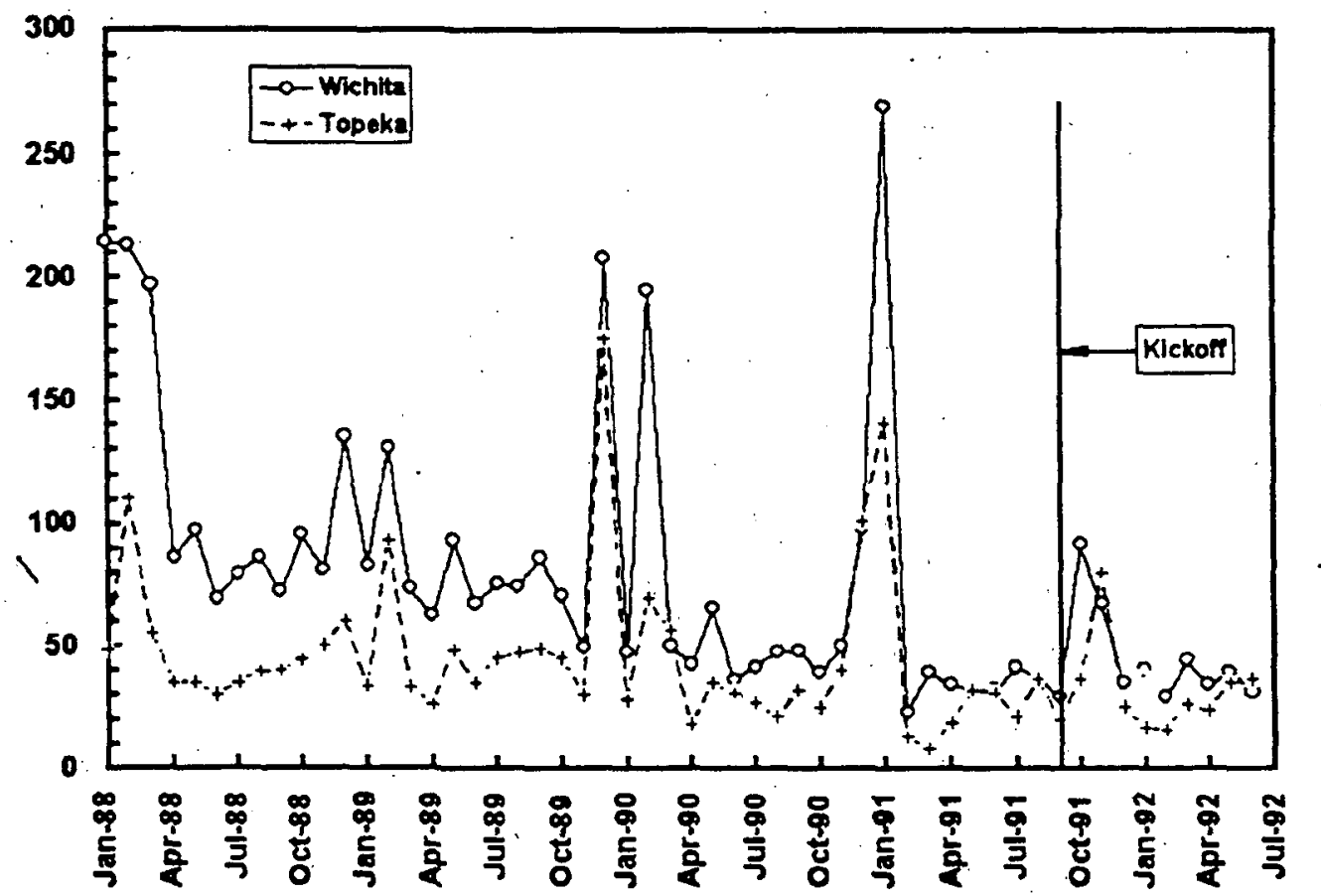


Since there exists a nationwide downtrend in alcohol involvement, a control for such a trend was needed. We used models of alcohol-related accidents allowing for a time trend, and for seasonal effects. We also considered the number of all accidents in Wichita, or the number of alcohol-related accidents in Topeka as controls. Both of these controls turned out to be very marginally significant (around $20 \%$ ); however; including them did not change the findings.

We found that the seasonal effect was not at all significant and that, overall, the intervention effect was not even marginally significant. Further, the intervention effect always had a positive sign, confirming the visual impression. Because of this "negative" result, more formal analyses using objective proxies for alcohol-related accidents were performed.

\section{MODELING PROXIES OF ALCOHOL-RELATED ACCIDENTS}

There are a number of possible proxies for alcohol-related accidents, including all nighttime accidents, nighttime injury accidents, nighttime single-vehicle accidents, and nighttime single-vehicle injury accidents. (Due to low numbers, fatal accidents could not be used in this study.) None of these proxies is a priori the "best" proxy. An accident class which has a very high proportion of alcohol-related accidents can have numbers so small that an effect may not be recognizable, whereas an effect might be recognizable in a class with a lower proportion of alcohol-related accidents, but with larger case numbers. Therefore, all four classes indicated above were used for the analyses.

The second question is: what are good comparison groups? Again, there is no a priori best choice. For each class of accidents, the same class at the comparison site is an obvious possibility. Another possibility is contrasting groups at the same site. Thus, for nighttime accidents, daytime accidents at the same site are also a possibility. Similarly, for nighttime injury accidents, daytime injury accidents as well as all nighttime accidents appear plausible. For nighttime single-vehicle accidents, nighttime multi-vehicle accidents, and daytime single-vehicle accidents are plausible. Finally, for nighttime single-vehicle injury accidents, all nighttime single-vehicle accidents, all nighttime injury accidents, and also daytime single-vehicle injury accidents are possible choices. To determine which of these choices were actually suitable as comparison groups, models for the time prior to the intervention were studied, and we only used those where the effect of the comparison group was significant at least at the $20 \%$ level. In addition to the term for the comparison group, a time trend and a seasonal component were allowed.

Often, comparison data are used to calculate ratios of the study accidents to the comparison accidents and to analyze them, implicitly assuming that such ratios would remain constant over time, or at least show only a simple time trend. Our experience has shown that, in general, this is not a good practice. Often, such ratios show complicated time patterns which are not readily explainable, so that one cannot exclude the possibility that changes observed at the time of the studied intervention are not also due to these unexplained factors. It is also easy to see that in some cases ratios can give grossly misleading models. It is preferable to use a comparison 
variable as an independent variable in a regression model, because such a variable includes a constant ratio as a special case, but allows modeling more complicated conditions.

A large number of models were developed. We only retained those where the comparison variable turned out to be suitable (as defined above), and an intervention effect appeared significant, both at least at the $20 \%$ level. Trends and seasonal patterns were omitted if they did not reach this level. Because of the large number of models tried, the significance levels for the models retained (as obtained by standard statistical programs) are not valid; the actual significance levels will be lower because of the possibility that a model's significant effect was due to chance alone.

The resulting models and pertinent parameters are: .

Model 1: All nighttime accidents, using all daytime accidents as a comparison: an intervention effect of -14 accidents per month with a standard error of 8 (significance level 0.08 ), compared with a mean number of 148. The autocorrelation of the residuals was 0.17 .

Model 2: Nighttime single-vehicle accidents, mean value 68 , with daytime singlevehicle accidents as a comparison group, an effect of -23 accidents per month with a standard error of 6 (significance 0.0001 ). The autocorrelation of the residuals was 0.36 .

Model 3: Nighttime single-vehicle accidents, using all nighttime accidents as a comparison group, an effect of -13 accidents per month with a standard error of 4 (significance level of .001), and an autocorrelation of the residuals of 0.09 .

Model 4: Nighttime single-vehicle accidents, using the corresponding accidents in Topeka as a comparison group, with an effect of -13 accidents per month and a standard error of 4 (significance level 0.004), and autocorrelation of the residuals of 0.30 .

These findings suggest that the Trifecta program had a real effect, but the autocorrelations of the residuals are, with one exception, high. This suggests systematic deviations between the models and the actual data. Therefore, the residuals were thoroughly inspected and analyzed.

\section{REVIEW OF RESIDUALS}

We analyzed the residuals for the four models described, above. If the models were good, and the intervention had an effect, one would expect random fluctuations around a constant level until the intervention, a drop at the time of the intervention, or somewhat later, or perhaps a gradual decline. This was not the case. Three models show essentially the same pattern: large positive residuals during early 1988 , rapidly declining, and then increasing, reaching high values around the middle of 1990. The residuals then follow a consistent decline until the end. The values during the intervention period are not lower than many values in 1988 and 1989. 
This indicates that there are unexplained factors affecting these classes of accidents in Wichita. Without identifying and including them in the model, no valid conclusion on an effect of the intervention can be drawn.

We used an unconventional approach to determine whether there was any indication of an effect of the intervention. Since there appeared to be a steady downtrend beginning about the middle of 1990 , we used only the data from January, 1990 on. A regression line was fitted to the data points before the intervention, and another one for the data points during the intervention. In two cases, the second regression lines are virtual continuations of the first ones; in the other cases, they show substantial drops. In the case of nighttime single-vehicle accidents, no drop appears when all nighttime accidents are used for comparison, but a drop appears when daytime single-vehicle accidents, or nighttime single-vehicle accidents in Topeka are used for comparison. This suggests that any drop affected all nighttime accidents in Wichita, not just single-vehicle accidents. On the other hand, nighttime accidents in Wichita showed no reduction compared with daytime accidents in Wichita.

We also fitted complete models to the data for the shorter periods beginning in July, 1990. The results indicated an effect of -12 for all nighttime accidents, with a standard error of 9 ; an effect of -8 with a standard error of 7 for nighttime single- vehicle accidents compared with daytime single-vehicle accidents; an effect of +4 with a standard error of 6 when compared with all nighttime accidents; and an effect of -5 with a standard error of 10 when compared with nighttime single-vehicle accidents in Topeka.

The residuals patterns in the four models above suggested a cyclical pattern with a period of two years. The cycle appeared to peak initially in the Spring of 1988, drop to a minimum in the Spring of 1989, and then peak again in the Spring of 1990 . The pattern continued on through one additional cycle, ending in the Spring of 1992. Removing this apparent cycle ${ }^{4}$ in the four retained models as defined above reduced the autocorrelation considerably while increasing the magnitude and significance of the effect, viz:

Model 1: An effect of -28 accidents per month; standard error of 7 (significance level 0.0004$)$; autocorrelation of the residuals of -.05 .

Model 2: An effect of -28 accidents per month; standard error of 5 (significance level 0.0001 ); autocorrelation of the residuals of 0.12 .

Model 3: An effect of -16 accidents per month; standard error of 4 (significance level 0.0004 ); autocorrelation of the residuals of 0.06 .

Model 4: An effect of -27 accidents per month; standard error of 5 (significance level 0.0004 ); autocorrelation of the residuals of 0.14 .

The cyclical term was highly significant in all of the models except model 3 (significance level 0.12 ). Figure $\mathrm{C}-5$ shows how model 1 with a cyclical term (and a

\footnotetext{
${ }^{4}$ The cycle was removed by the addition of a variable that varied sinusoidally with time.
} 
step intervention term) fits the data. An analysis of the residuals for the models indicated no apparent systematic fluctuations of the residuals.

While these "cyclical" models of two proxies of alcohol-related accidents appear to point to a program effect, we are still left to explain why such a two-year cycle is a plausible correlate of these alcohol-related proxies. To date, we have been unable to find any such explanation that could be traced to events which occurred in Wichita. We note, however, that smoothed time series of random processes sometimes exhibit such "cycles," so that their appearance in the residuals could be purely random and not necessarily due to systematic deviations between the original model and the data. Then, removing these cycles with an external variable could be appropriate, and the observed reduction in the alcohol-related proxies could be due to the combined enforcement effort.

Figure C-5: Cyclical Model of Nighttime Accidents in Wichita

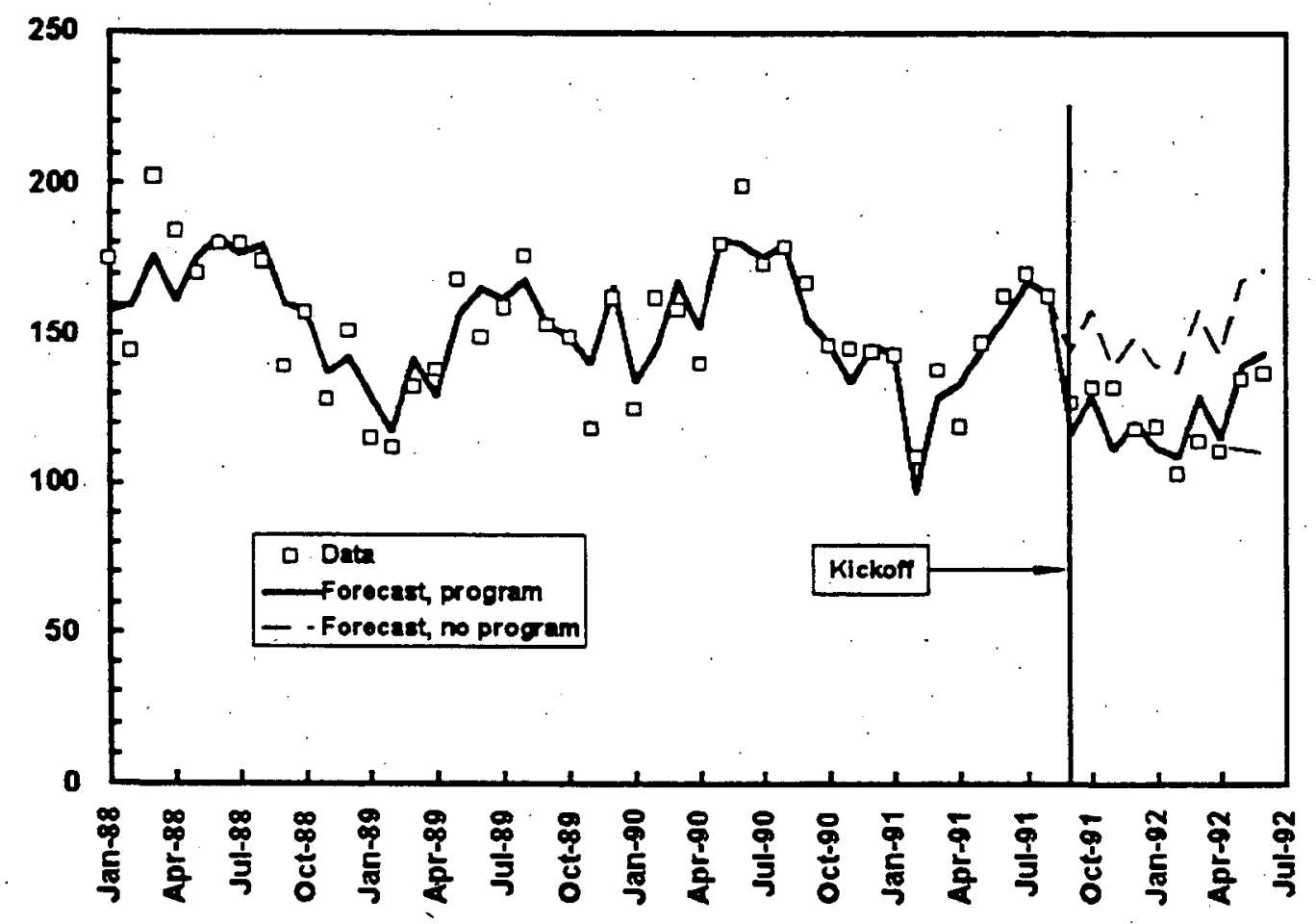

\section{ARIMA MODELS}

Finally, Box and Jenkin's ARIMA modeling procedure was applied to all dependent variables that could plausibly be considered proxies for alcohol-related crashes. Several potential indicators of speeding and restraint use were also examined using ARIMA models. With respect to alcohol-related proxies, we examined: 
- All nighttime accidents;

- Nighttime injury accidents;

- Nighttime single-vehicle accidents; and

- Nighttime single-vehicle injury accidents.

Various series were used as a control, including series of Wichita accidents and series of Topeka accidents. Graphs depicting the results of some of these analyses using Topeka as a contrọl are shown in Figure C-6, Figure C-6, Figure C-7, and Figure C-9. The graphs show the raw data taken from the Kansas Department of Transportation database, plus ARIMA forecasts based on these data. Forecasts of accidents without the intervention coinciding with the Traffic Trifecta program are indicated by the dotted lines, while forecasts of accidents with the intervention coinciding with the Traffic Trifecta program are indicated by the solid lines. The differences between the two forecasts suggest a highly significant reduction $(p<.005)$ in alcohol-related accidents in Wichita. The greatest reduction (35\%) was for nighttime single-vehicle accidents. Reductions in the other three classes of accidents ranged from $20 \%$ to $23 \%$ (see Table C-1).

Figure C.6: Nighttime Accidents in Wichita, Topeka as a Control

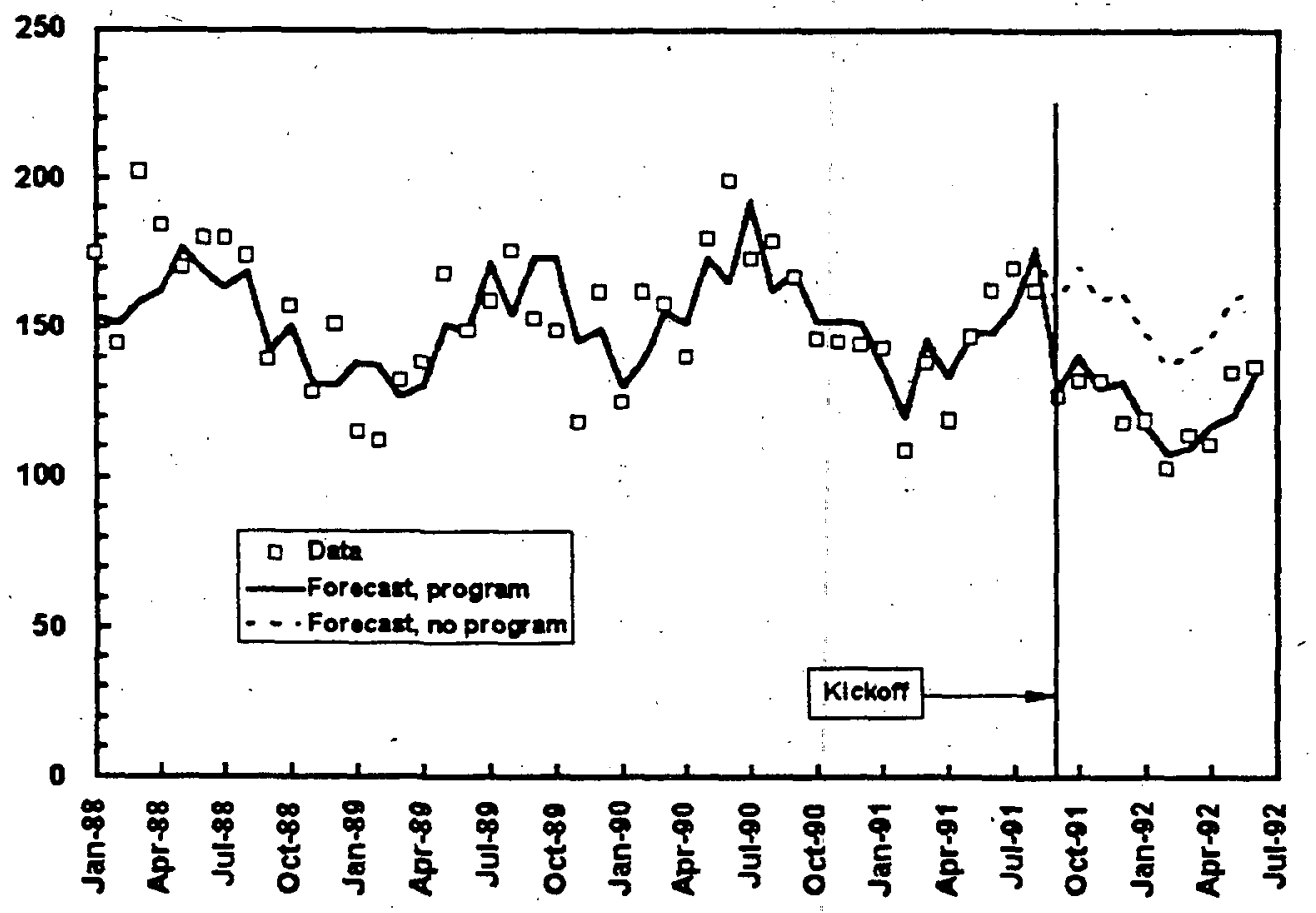


Figure C-8: Nighttime Single Vehicle Accidents in Wichita, Topeka as a Control

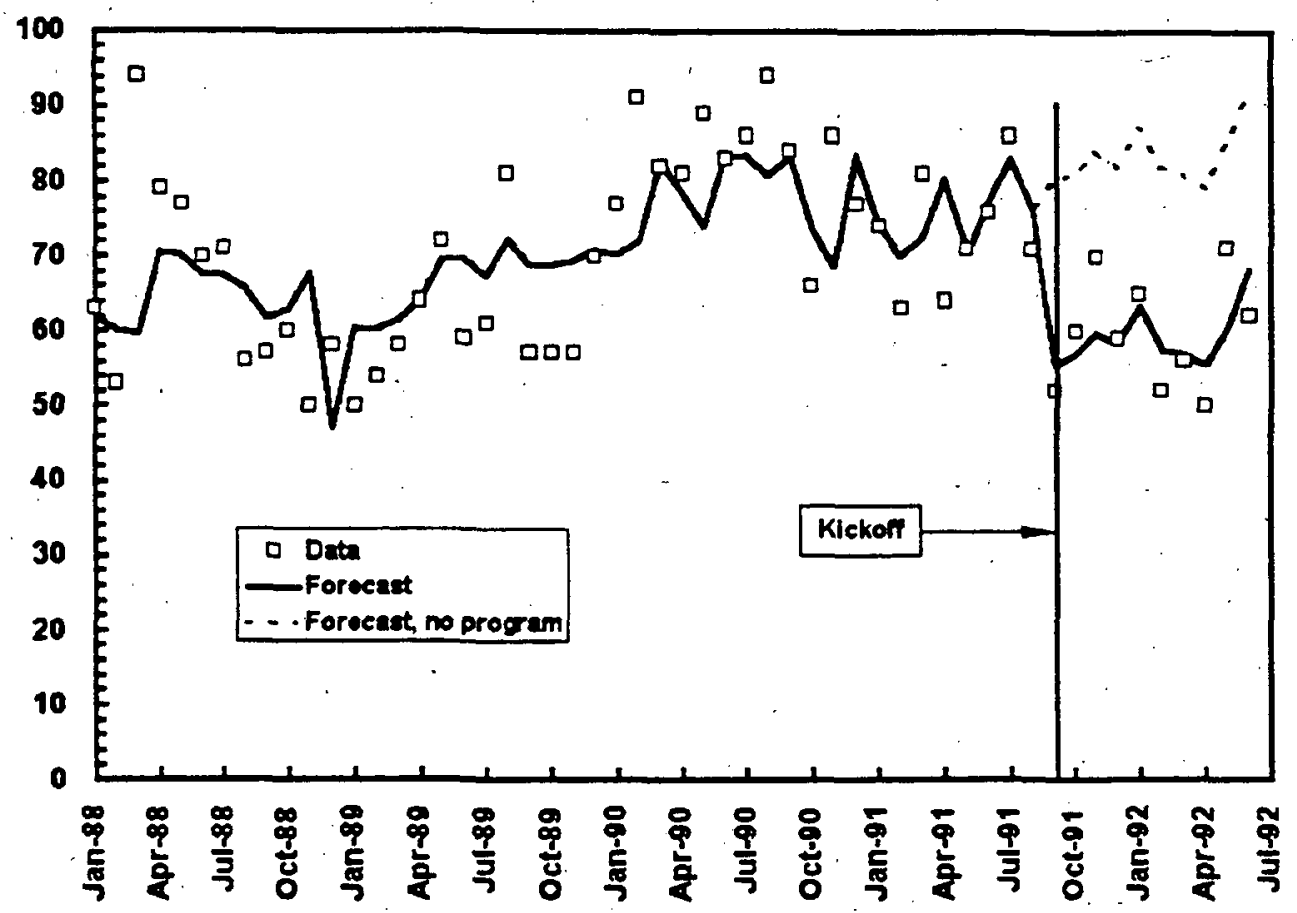

Figure C-7: Nighttime Injury Accidents in Wichita, Topeka as a Control

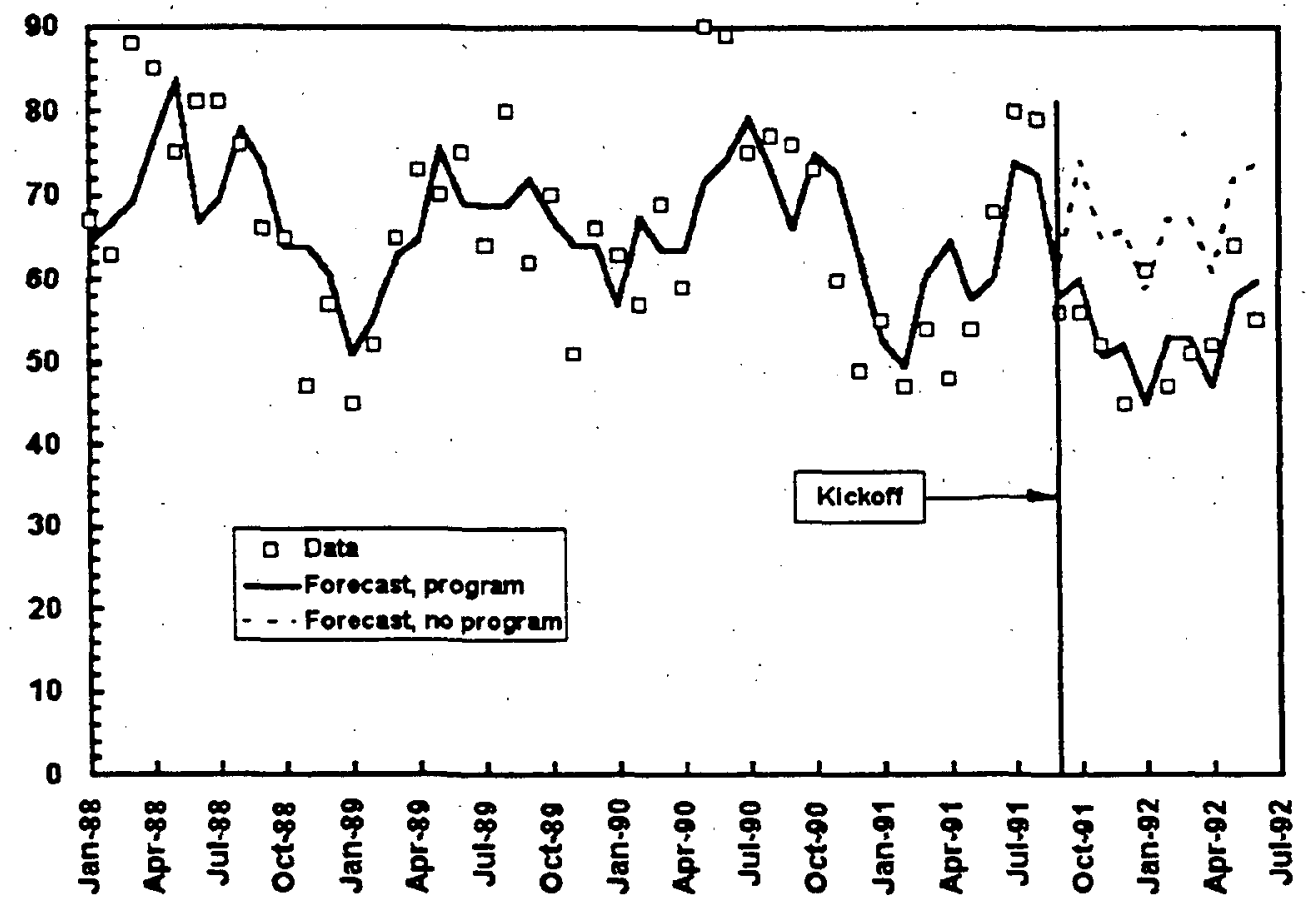


Figure C.9: Nighttime Single-Vehicle Injury Accidents in Wichita, Topeka as a Control

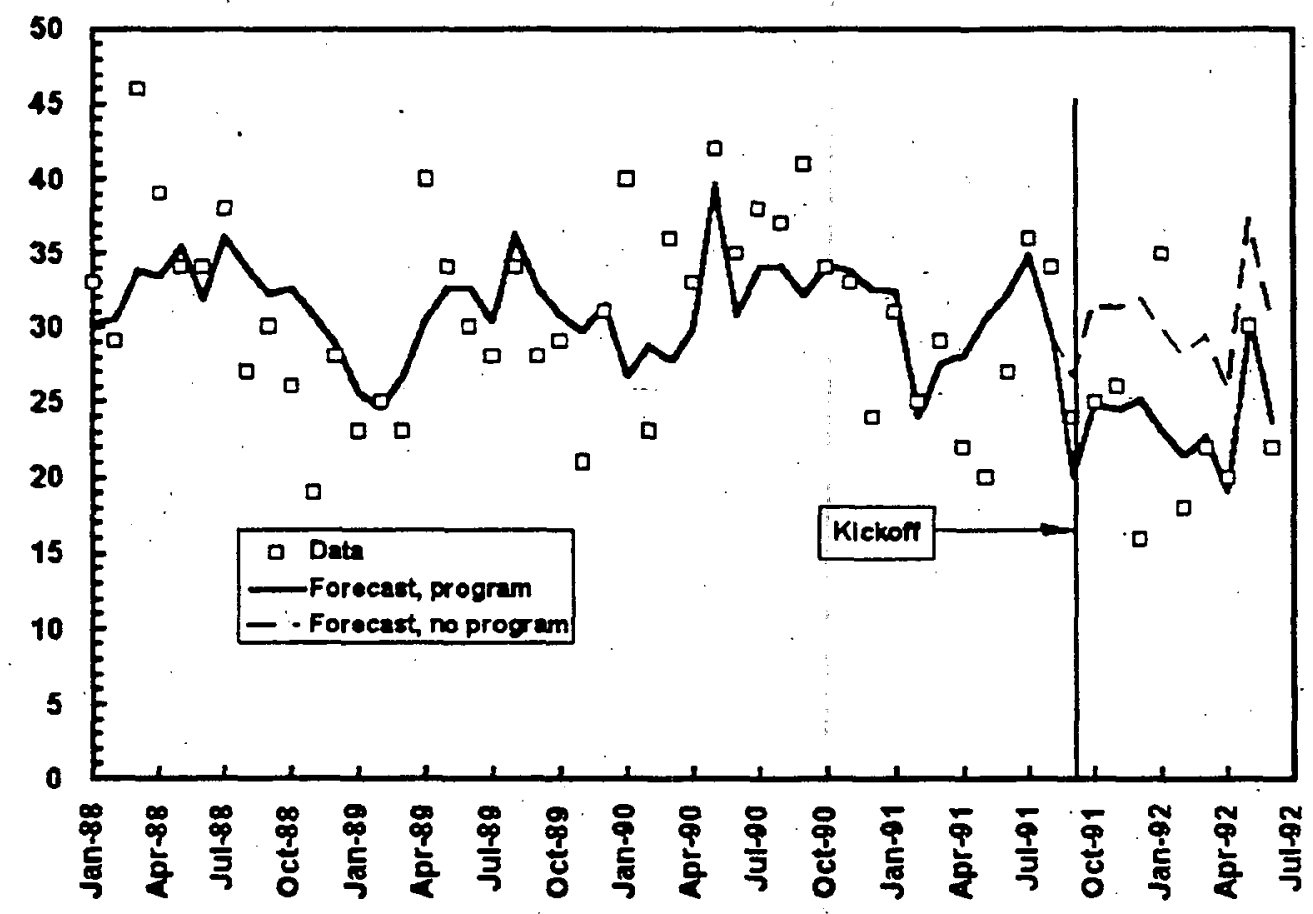

Table C-1: Summary of Results of ARIMA Analyses of Proxies of Alcohol-Related Accidents in Wichita

\begin{tabular}{|l|l|}
\hline \multicolumn{1}{|c|}{ Type of Accident } & $\begin{array}{c}\text { Reduction in Accidents as } \\
\text { a \% of the Mean }\end{array}$ \\
\hline \hline Nighttime & $20 \%(30 / 148)$ \\
\hline Nighttime Injury & $21 \%(14 / 65)$ \\
\hline Nighttime Single-Vehicle & $35 \%(24 / 69)$ \\
\hline Nighttime Single-Vehicle Injury & $23 \%(7 / 30)$ \\
\hline
\end{tabular}

